\title{
USDOE TOP-OF-RAIL LUBRICANT PROJECT
}

\author{
Final Report
}

to

\author{
U.S. Department of Energy \\ Office of Transportation Technology \\ Office of Heavy Vehicles Technologies
}

\begin{abstract}
Argonne National Laboratory
Mohumad F. Alzoubi, George R. Fenske, Robert A. Erck Energy Technology Division / Tribology Section
\end{abstract}

Amrit S. Boparai

Chemical Technology Division / Analytical Chemistry Laboratory

Argonne National Laboratory

Feb. 2000 


\section{Disclaimer}

This report was prepared as an account of work sponsored by an agency of the United States Government. Neither the United States Government nor any agency thereof, nor The University of Chicago, nor any of their employees or officers, makes any warranty, express or implied, or assumes any legal liability or responsibility for the accuracy, completeness, or usefulness of any information, apparatus, product, or process disclosed, or represents that its use would not infringe privately owned rights. Reference herein to any specific commercial product, process, or service by trade name, trademark, manufacturer, or otherwise does not necessarily constitute or imply its endorsement, recommendation, or favoring by the United States Government or any agency thereof. The views and opinions of document authors expressed herein do not necessarily state or reflect those of the United States Government or any agency thereof, Argonne National Laboratory, or The University of Chicago. 


\section{CONTENTS}

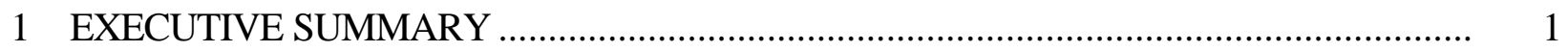

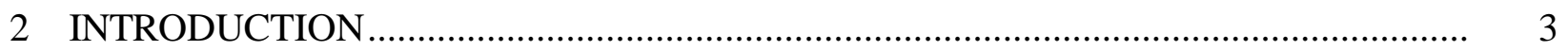

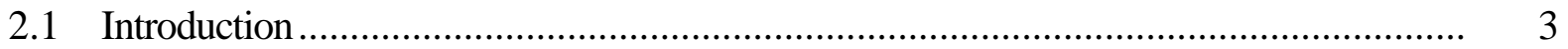

2.2 Literature Review........................................................................................... 3

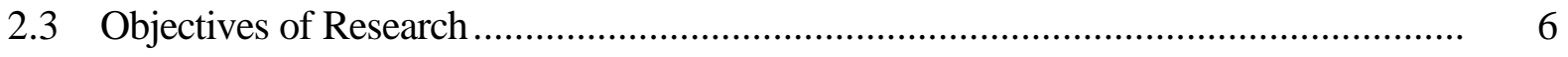

2.4 Research Approach ................................................................................................. 6

3 LA 4000 WHEEL AND RAIL SIMULATOR TESTING FACILITY …………................... 7

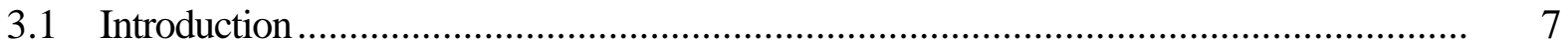

3.2 The Testing Facility.................................................................................................. 7

3.3 System Modification by Argonne ………………….................................................. 9

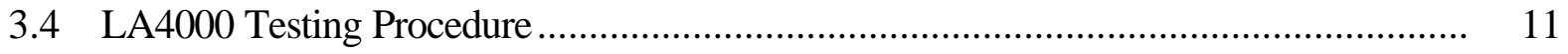

3.5 Field Parameter Simulation.............................................................................. 12

$4 \quad$ EXPERIMENTAL RESULTS AND DISSCUSSION ......................................................... 13

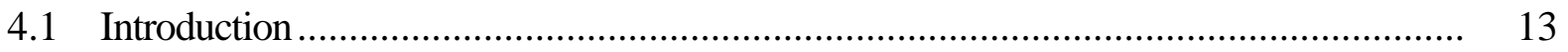

4.2 Friction/Time Results..................................................................................... 13

4.2.1 Effect of Angle of attack......................................................................... 13

4.2.2 Effect of Arm Load .................................................................................... 13

4.2.3 Effect of Lubricant Volume Quantity.............................................................. 14

4.3 By-Product Results ............................................................................................ 15

4.3.1 Volatile Samples .............................................................................. 15

4.3.2 Semivolatile Samples................................................................................ 19

5 CONCLUSIONS AND RECOMMENDATIONS ……………………............................ 28

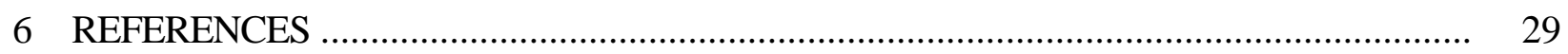




\section{TABLES}

1 Relative composition of analytes in collected gas .................................................. 22

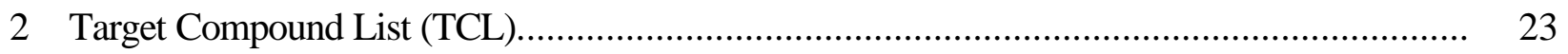

3 Composition of TOR Lubricant 483-98-6004 before use............................................. 24

4 Composition of TOR Lubricant 483-98-6004 after use............................................... 24

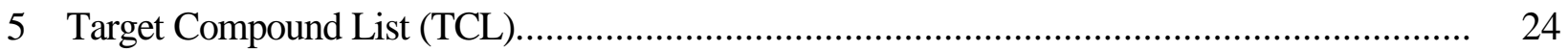

\section{FIGURES}

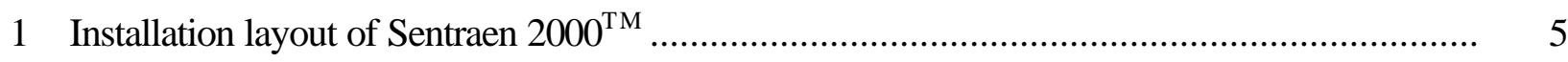

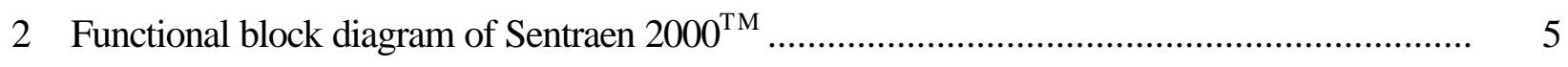

3 Basic operation of LA4000 facility: Powered wheel 11 rolls against unpowered wheel 10. In lubricant testing, deliberate misalignment of the wheel axes (angle 12) produces a slip rate; addition of TOR lubricant in wheel-contact area causes lateral-force changes that indicate the lubricity and durability of the lubricant.

4 Schematic diagram of LA4000 machine: An electric motor (19) drives wheel 11, which is mounted so that it can swivel around a pivot (31) while it is in contact with wheel 10. Lateral and vertical loads are carried by thrust bearings (26). Loading weight $\mathrm{L}$ is hung on loading arm 28; motor speed is kept constant by a feedback system. During operation, application of an angle of attack to wheel 11 causes carriage 17 to slide sideways, and this force is transmitted to a data-acquisition computer; software then plots force vs. time.

5 Argonne-modified LA4000 system: Programmed syringe pump provides lubricant through a nozzle to the contact region, which is enclosed in Plexiglas to contain volatile by-products of the lubricant, which are then trapped by adsorption tubes. Vacuum pump then pulls out volatile samples for analysis.

6 Effect of angle of attack on lateral friction forces and consumption time under TOR lubrication, for rotational speed of $300 \mathrm{rpm}$, room temp., $5 \mu \mathrm{L}$ of TOR lubricant, and arm load of $5 \mathrm{lb}$. 


\section{FIGURES (CONT.)}

7 Effect of angle of attack on consumption time for TOR lubricant, for arm

load $=5 \mathrm{lb}$, rotational speed $=300 \mathrm{rpm}$, room temp., and $5 \mu \mathrm{L}$ of TOR lubricant.

8 Effect of arm load on lateral friction force and consumption time under TOR lubrication, for rotational speed of $300 \mathrm{rpm}$, room temp., and $5 \mu \mathrm{L}$ of TOR lubricant..............

9 Effect of lubricant quantity on lateral friction forces and consumption time, for arm load of $5 \mathrm{lb}$, room temp., and $1.7^{\circ}$ angle of attack.

10 Friction-time results for runs 2, 3, and 5 for arm load $5 \mathrm{lb}, 300 \mathrm{rpm}$, period of $5 \mathrm{hr}$, room temp., and total of $0.25 \mathrm{~mL}$ TOR lubricant.

11 GC/MS intensity versus time for volatile Run 1, room sampling, and no motion.

$12 \mathrm{GC} / \mathrm{MS}$ intensity versus time for volatile Run 2 , dry contact, $0^{\circ} \mathrm{AOA}$, and motion.

$13 \mathrm{GC} / \mathrm{MS}$ intensity versus time for volatile Run 3 , dry contact, $1.7^{\circ} \mathrm{AOA}$, and motion.

14 GC/MS intensity versus time for volatile Run 4, TOR lubrication, ${ }^{\circ} \mathrm{AOA}$, and motion.

$15 \mathrm{GC} / \mathrm{MS}$ intensity versus time for volatile Run 5, TOR lubrication, $1.7^{\circ}$ AOA, and motion.

$16 \mathrm{GC} / \mathrm{MS}$ intensity versus time for semivolatile or TOR lubricant before use.

17 GC/MS intensity versus time for semivolatile or TOR lubricant after use.

18 Mass spectrum of 1,2 propanediol from sample standard from the computerized library spectra. 


\title{
U.S. DEPARTMENT OF ENERGY TOP-OF-RAIL LUBRICANT PROJECT
}

\author{
by \\ M.F. Alzoubi, G.R. Fenske, R.A. Erck, and \\ A.S. Boparai
}

\section{EXECUTIVE SUMMARY}

Lubrication of wheel/rail systems has been recognized for the last two decades as a very important issue for railroads. Energy savings and less friction and wear can be realized if a lubricant can be used at the wheel/rail interface. On the other hand, adverse influences are seen in operating and wear conditions if improper or excessive lubrication is used. Also, inefficiencies in lubrication need to be avoided for economic and environmental reasons.

The top-of-rail (TOR) lubricant concept was developed by Texaco Corporation to lubricate wheels and rails effectively and efficiently. Tranergy Corporation has been developing its SENTRAEN $2000^{\mathrm{TM}}$ lubrication system for the last ten years, and this revolutionary new high-tech on-board rail lubrication system promises to dramatically improve the energy efficiency, performance, safety, and track environment of railroads. The system is fully computer-controlled and ensures that all of the lubricant is consumed as the end of the train passes. Lubricant quantity dispensed is a function of grade, speed, curve, and axle load. Tranergy also has its LA $4000^{\mathrm{TM}}$ wheel and rail simulator, a lubrication and traction testing apparatus.

The primary task of this project was collecting and analyzing the volatile and semivolatile compounds produced as the lubricant was used. The volatile organic compounds were collected by Carbotrap cartridges and analyzed by adsorption and gas chromatography/mass spectrometry (GC/MS). The semivolatile fraction was obtained by collecting liquid that dripped from the test wheel. The collected material was also analyzed by GC/MS. Both of these analyses were qualitative. The results indicated that in the volatile fraction, the only compounds on the Environmental Protection Agency's (EPA) Superfund List of Analytes detected were contaminants either in the room air or from other potential contamination sources in the laboratory. Similarly, in the semivolatile fraction none of the detected compounds are on the EPA's Superfund List of Analytes. The major compound in the semivolatile fraction is 1,2-propanediol, which was also found as the major component of the TOR lubricant before testing. Other compounds found in trace quantities either were present in the TOR lubricant or were small fragments from the polymeric component of the TOR lubricant.

The second task for Argonne in this project was to investigate the effects of axle load, angle of attack, and quantity of lubricant on lateral friction forces, as well as the consumption time of the TOR 
lubricant. The second task was to collect and qualitatively identify any volatile and semivolatile compounds produced upon use of the TOR lubricant.

Effects of angle of attack, axle load, and quantity of the TOR lubricant 483-98-6004 on lateral friction forces and consumption time have been investigated by the Tribology Section at Argonne National Laboratory. The results show that increases in angle of attack increase the friction forces and reduce consumption time for the lubricant. Also, increases in axle load increase the rate at which the lubricant is consumed. Finally, the more TOR lubricant that is added to the wheel/rail interface, the longer the time needed for the lubricant to be consumed totally. This suggests that lubricant quantity must be calculated precisely according to various conditions such as speed, axle load, angle of attack, and number of cars in the train. 


\section{INTRODUCTION}

\subsection{INTRODUCTION}

The friction and wear of railroad-car wheels caused by rolling resistance has been the subject of many technical studies in the US, as has been the larger area of track/train dynamics. Excessive friction between car wheels and rail increases locomotive fuel consumption, reduces train speed, and causes damage, such as track degradation, wheel and rail wear, and hunting (hunting is caused by disturbing car, track, and traction forces; although the wheels continue at the same rotational velocity, they are on different radii because of coning). Thus, wheels slip on the rail and the axle adjusts to the larger radius; this effect is thereby transferred to the opposite rail and the hunting action continues, causing excessive wear on the rail [1]). The concept of rail lubrication has been developed over the years for several reasons:

1. Wear and friction at the wheel/rail interface is an important technological nuisance, costing U.S. railroads more than $\$ 2$ billion annually.

2. Maintenance and replacement of the rail is the biggest single dollar cost.

3. Current lubricants such as flange lubricants and application methods provide only a superficial solution to the problem, the root cause of which is excessive lateral force in the contact zone.

In 1995, railroads were estimated to carry more than $40 \%$ of the total freight, more than any transportation mode in the nation. The experience of the railroad industry and railroad equipment manufacturers indicates that about $\$ 250$ million could be saved annually from an effective program to reduce flange/rail friction by lubrication or other means [2]. Estimates indicate that about $1 / 3$ of the savings would come from increased fuel efficiency, 1/3 from less rail wear, and 1/3 from less wheel wear. Savings could vary considerably from place to place, depending on factors such as grades, curves, maximum speeds, and types of trains. Research with full-scale trains has shown that effective spray lubrication of the rail can result in fuel savings of up to $25 \%$ on highly curved track and about $5 \%$ on relatively straight track. For these reasons, many railroad companies and researchers are now dedicating intensive efforts to improve rail lubricants and the mechanisms of wheel/rail lubricating technology, and to develop application equipment as well.

\subsection{LITERATURE REVIEW}

Significant research has been conducted on the contact mechanisms between the wheel and the rail under dry and contaminated environments. Some of that research was theoretical, such as that by Johnson [3] and Kalker [4], both of whom examined the microstructure of the contact mechanism. 
Others, such as Love [5], established the Hertzian solution of elastic contacts, which can be used to predict contact shape, size, and pressure; Ohyama [6] examined the effect of lubrication on adhesion and slip.

Experimental research by Obara [7] predicted traction force behavior at the elliptical contact between the wheel and the rail. Other investigations in industrial research and field experience focused on the application of railroad lubricants to reduce friction and improve fuel efficiency. Among these are Kouhbor [8], Sims et al. [9], Kramer [10,11], Alp et al. [12], and Beret et al. [13]. Additional experimental research examined the TOR lubricant, such as, the series of tests conducted at the transportation test center in Pueblo, Colorado, in 1997 by the Association of American Railroads [14]. These investigations found that application of a lubricant on the rail gauge side of both curved and tangent track provides measurable benefits in reduced fuel consumption, increased wheel life, elimination of hunting, and reduced rail wear. Tranergy Corporation was among the companies that conducted the field test. Indeed, Tranergy has developed and produced a new system called SENTRAEN 2000 during the past decade to overcome these problems and improve fuel efficiency and productivity and to reduce track and equipment costs. SENTRAEN 2000 is a microprocessor-based on-board TOR lubrication system that can to dramatically improve the energy efficiency, performance, safety, and track environment of railroads. It is different from all current wheel/rail lubrication systems, which apply lubrication to the wheel flange or rail gauge side to reduce wheel flange friction. With SENTRAEN 2000, a consumable and environmentally safe water-based lubricant is applied by the last locomotive in precision, computer-controlled quantities so that all of the lubricant is consumed by the time the end of the train passes the TOR application point. The system is based on real-time data acquisition of train/track parameters and control of the lubricant quantity applied to the rails. Figures 1 and 2 show the installation and a functional block diagram of SENTRAEN 2000, respectively.

The top-of-rail lubricant (TOR) developed by Texaco in collaboration with Tranergy and the Illinois Institute of Technology at Chicago during the last ten years is a thin liquid, not messy grease. It is easy to clean and does not build up. It also features the following characteristics:

- No solids.

- Good mobility.

- High wetting ability.

- Little or no residue left after consumption.

- Does not increase full-service braking distance. 


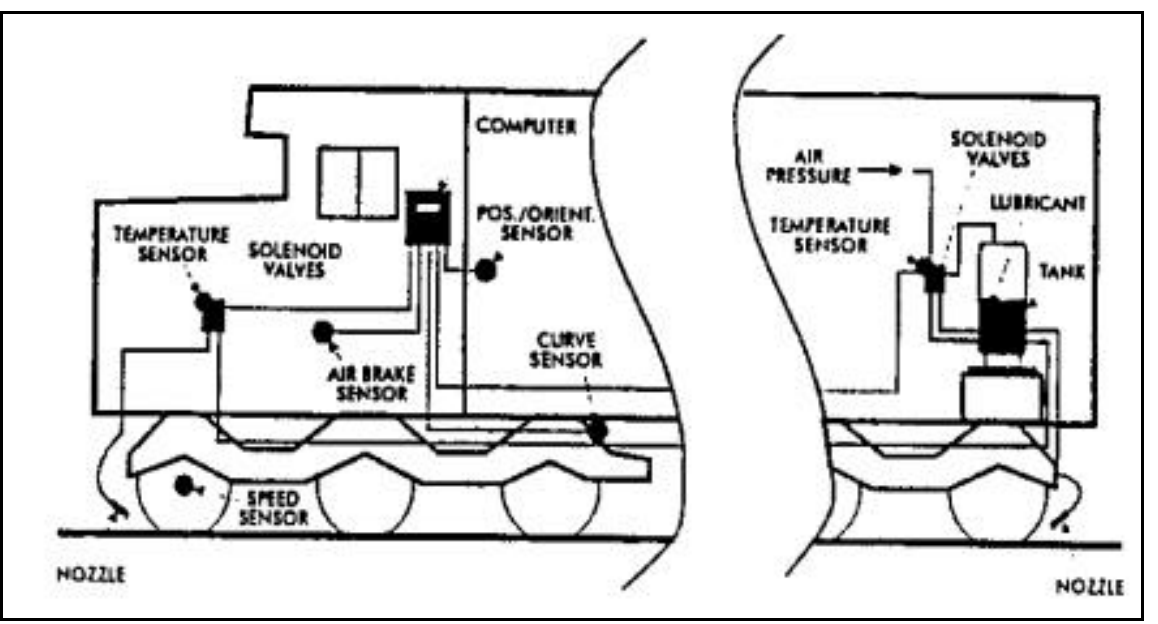

FIGURE 1 Installation layout of Sentraen $2000^{\mathrm{TM}}$

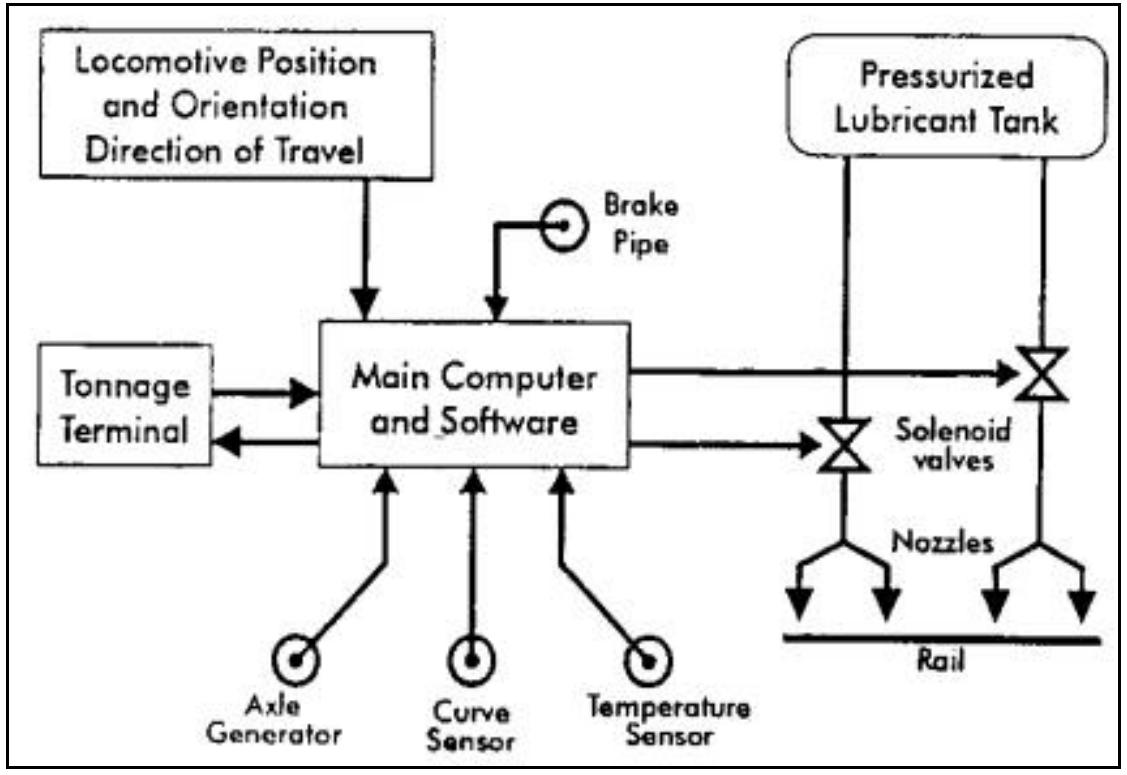

FIGURE 2 Functional block diagram of Sentraen $2000^{\mathrm{TM}}$ 
- Can be consumed by passage of 10 to 10,000 wheels, depending on quantity applied and track condition.

To date, however, an independent study of the performance and biodegradability of the TOR

lubricant has not been conducted. This motivated the U.S. Department of Energy to sponsor such a project at Argonne National Laboratory to complete and evaluate this lubricant.

\subsection{OBJECTIVES OF RESEARCH}

The objectives of the research conducted at Argonne are centered on:

1. Collecting, analyzing, and evaluating volatile and semivolatile compounds produced during use of the TOR lubricant and determining if the degradation compounds are environmentally safe, biodegradable, and nontoxic.

2. Effect of axle load, angle of attack, and quantity of TOR lubricant on lateral friction forces and consumption time of the lubricant.

\subsection{RESEARCH APPROACH}

The following approach was implemented for achieving the above described objectives:

1. Installation of the Tranergy LA4000 wheel and rail simulator testing apparatus at Argonne.

2. In order to collect and analyze volatile and semivolatile samples of TOR lubricants, scientists in Argonne's Tribology Section modified the LA4000 system by enclosing the contact zone of the simulator's two wheels. The volatile and semivolatile byproducts of the lubricant are then trapped by adsorption tubes; this will be covered in detail in Section 3.

3. After collection, the samples were sent to Argonne's Analytical Chemistry Laboratory to be analyzed by GC/MS.

4. Effect of angle of attack, loads, and quantity of TOR lubricant on friction forces and consumption time of the lubricant will be investigated with the LA4000 wheel and rail simulator. 


\section{LA 4000 WHEEL AND RAIL SIMULATOR TESTING FACILITY}

\subsection{INTRODUCTION}

The Tranergy LA4000 wheel and rail 1/12.5-scale simulator is a lubrication and traction testing facility. It is designed to test lubricity and durability of lubricants under a broad range of condition [15]. This is the only machine available today that successfully simulates field conditions of rail/wheel lubrication, as follows:

1. Contact stress and its distribution are simulated by using the Hertz theory of elasticity.

2. Slip is simulated by applying an angle of attack that is kept constant throughout a test period and is independent of wheel wear.

3. Real-world three-dimensional contact is simulated, allowing the lubricant to escape of the contact area. Lateral creep actually pushes the lubricant and out of the contact track.

\subsection{THE TESTING FACILITY}

The LA4000 can also be used to test other lubricants that require specific simulation of contact stress and slip for the desired application. The facility measures the actual lateral force exerted by a wheel set at a desired angle of attack and lubrication level.

The basic concept of the testing facility is shown in Fig. 3. Two wheels, one powered and the other rolling freely, roll against each other. The wheels are profiled to produce the contact stress of the field condition being simulated in the laboratory for a load calculated by Hertz theory. For lubricant testing, the wheel axes are purposely misaligned by a specific angle that produces the slip rate of the field condition in which the lubricant is used. After the application of a small quantity of the lubricant (e.g., $5 \mu \mathrm{l}$ ) in the wheel-contact area, the lateral-force changes become a performance measure of the lubricity and durability of the lubricant.

Figure 4 is a schematic diagram of the LA4000 machine. The two wheels are mounted so as to allow their quick and easy replacement. The lower wheel is driven by a DC electric motor through a gear reducer, a spline bearing, a spline shaft, and a flexi-coupling. The whole assembly of the lower wheel is mounted on a stiff plate that can swivel around a pivot mounted in the base plate. The pivot is located precisely below the contact point of the two wheels. The upper 


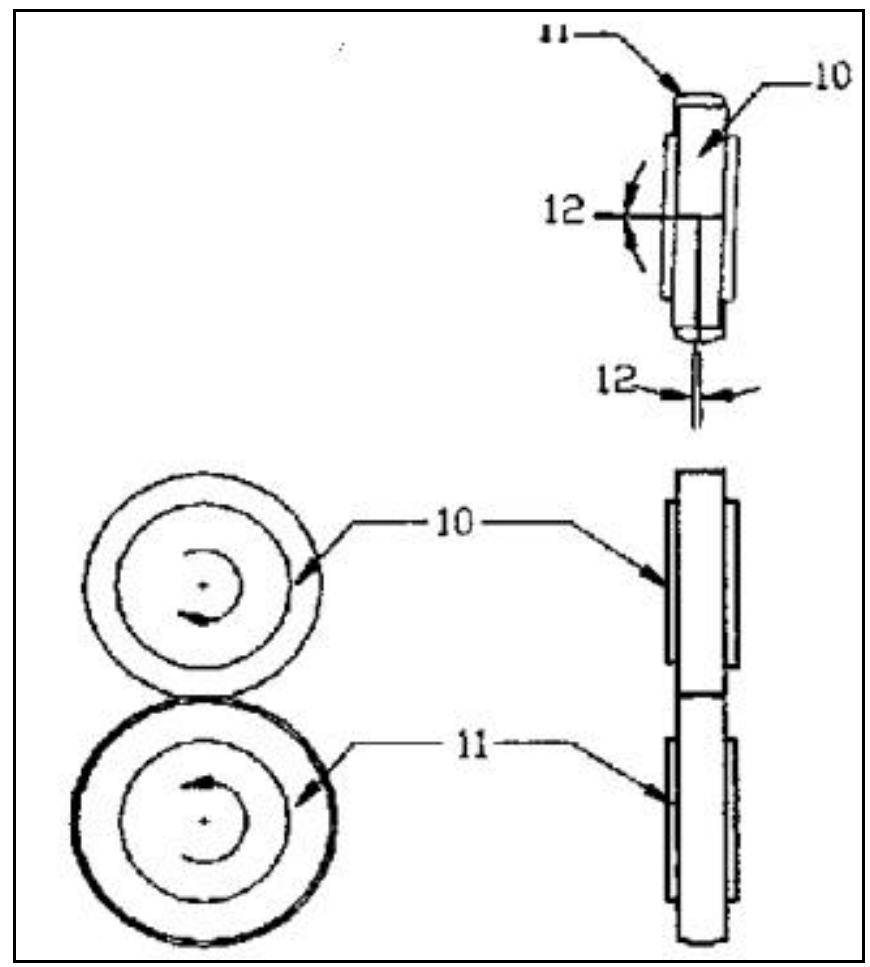

FIGURE 3 Basic operation of LA4000 facility: Powered wheel 11 rolls against unpowered wheel 10. In lubricant testing, deliberate misalignment of the wheel axes (angle 12) produces a slip rate; addition of TOR lubricant in wheel-contact area causes lateral-force changes that indicate the lubricity and durability of the lubricant.

(unpowered) wheel is mounted in a swinging cantilever-type carriage that carries the requisite load at the end of the beam. The wheels can rotate freely while carrying lateral and vertical loads. A weight is hung at the end of the loading arm.

It should be noted here that the application of $1 \mathrm{lb}$ arm load causes an increase of $4 \mathrm{lb}$ of the wheel load, and also the wheel load with no arm weight, is $15.25 \mathrm{lb}$. Motor speed is kept constant through an electric feedback control system. During operation, application of an angle of attack causes the carriage to slide to the left, causing a load button to push against a load cell. This lateral force is transmitted to the data acquisition computer; software then plots force values as a function of time on a graph. 


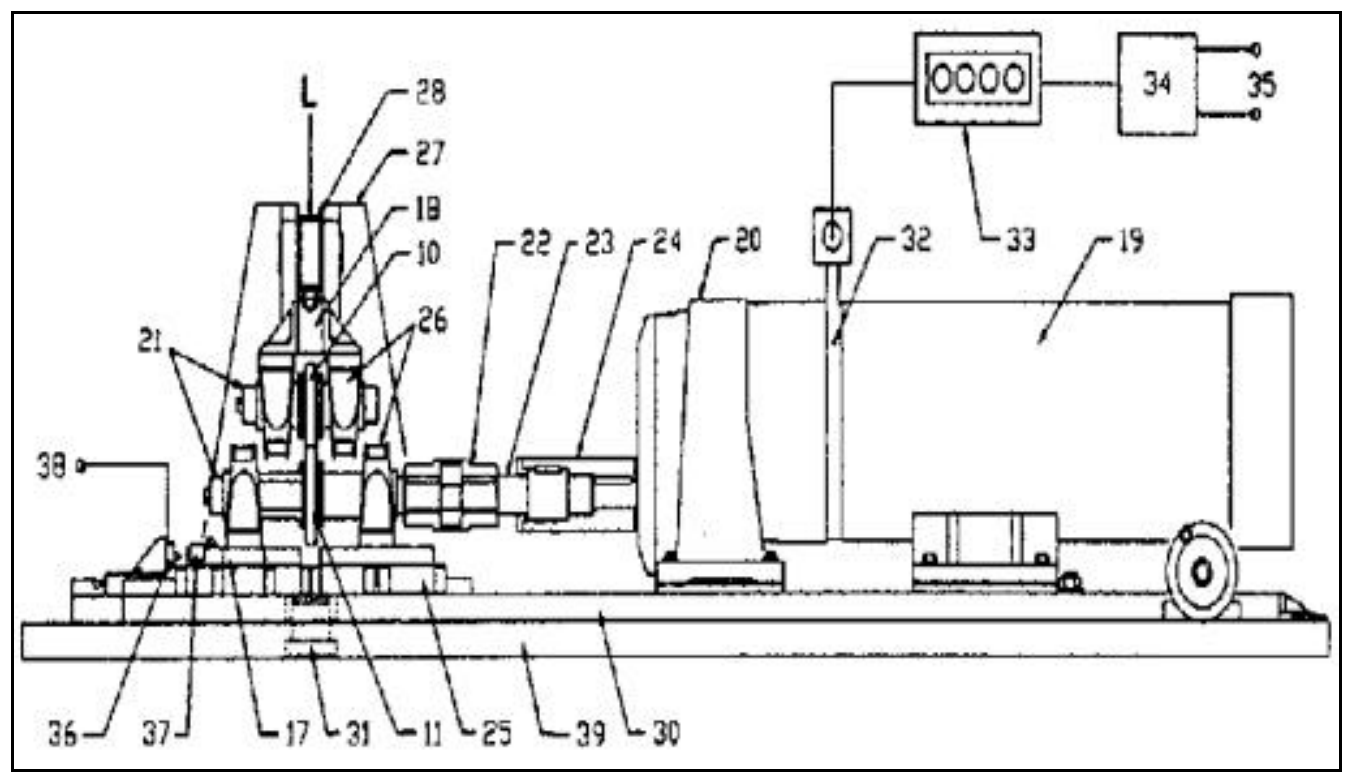

FIGURE 4 Schematic diagram of LA4000 machine: An electric motor (19) drives wheel 11, which is mounted so that it can swivel around a pivot (31) while it is in contact with wheel 10. Lateral and vertical loads are carried by thrust bearings (26). Loading weight $L$ is hung on loading arm 28; motor speed is kept constant by a feedback system. During operation, application of an angle of attack to wheel 11 causes carriage 17 to slide sideways, and this force is transmitted to a data-acquisition computer; software then plots force vs. time.

\subsection{SYSTEM MODIFICATION BY ARGONNE}

The LA4000 simulator was designed to measure the lubricity and durability of lubricants under a broad range of conditions. But because the major reason for this project was to evaluate and analyze the TOR lubricant environmentally before and after it has been consumed, it was necessary for Argonne scientists to modify the system in order to collect the volatile and semivolatile components of the lubricant itself. Figure 5 is a schematic component diagram of the modified portion of LA4000, including the two wheels as numbered on the figure; the modified arrangement is as follows:

1. Programmed lubricant syringe pump controls the flow rate and period of lubricant application at the contact region.

2. Valve \#2 controls the amount of the lubricant provided. 


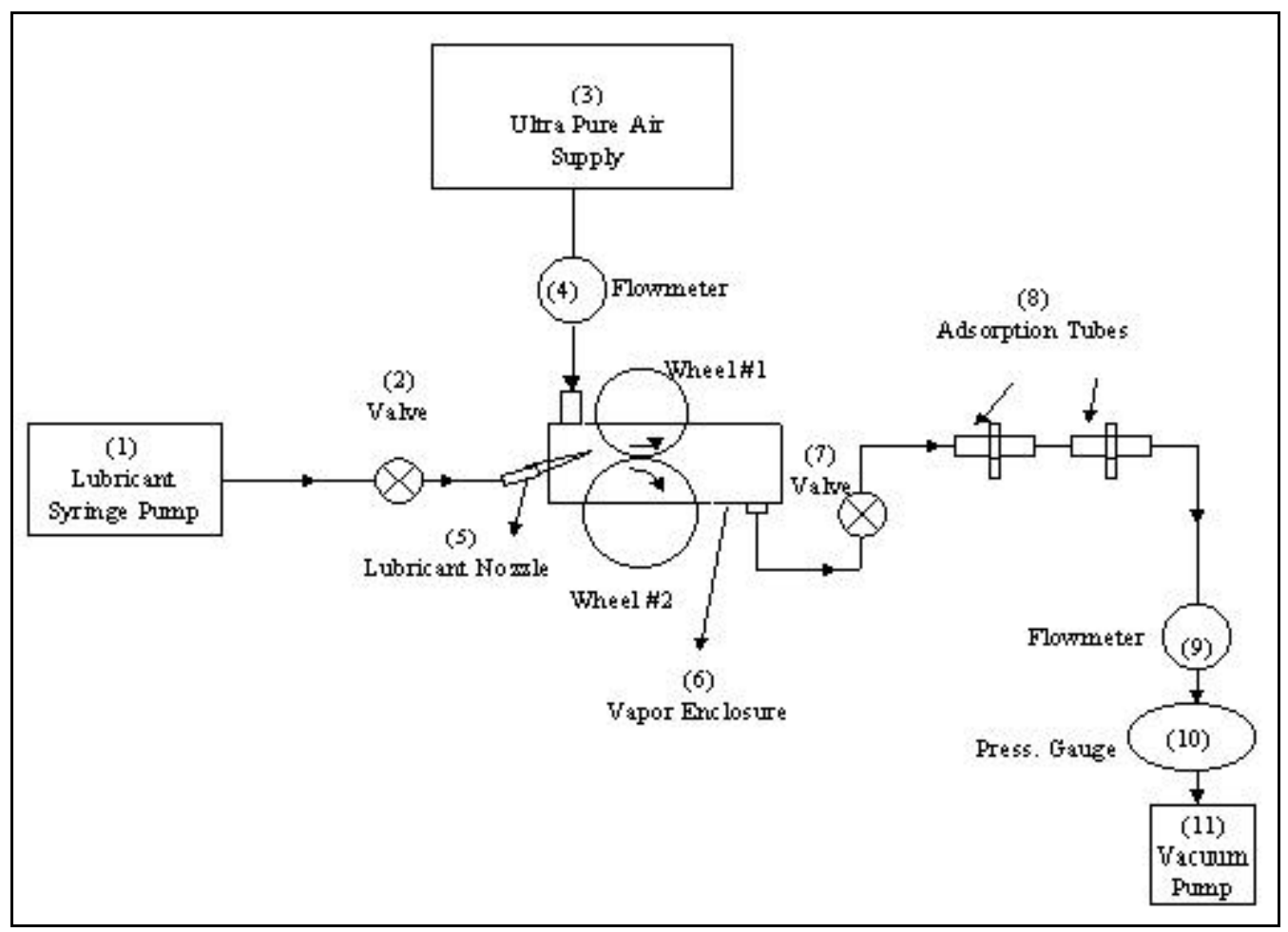

FIGURE 5 Argonne-modified LA4000 system: Programmed syringe pump provides lubricant through a nozzle to the contact region, which is enclosed in Plexiglas to contain volatile by-products of the lubricant, which are then trapped by adsorption tubes. Vacuum pump then pulls out volatile samples for analysis.

3. Ultrapure air supplier maintains a positive pressure inside the vapor enclosure.

4. Flowmeter \#4 measures the flow rates from the air supplier.

5. Lubricant nozzle supplier provides lubricant to the contact region.

6. Vapor enclosure made of Plexiglas to contain volatile by-products of the lubricant.

7. Valve \#7 controls the amount of volatile sample to be collected.

8. Adsorption tubes to adsorb and hold the volatile samples.

9. Flowmeter \#9 measures the flow rates of the collected vapor.

10. Pressure gauge measures pressure of the collected sample. 
11. Vacuum pump is used to draw out a volatile sample.

It should be noted here that the flow rate in the flowmeter \#4 should be higher than that in flowmeter \#9 in order to maintain positive pressure inside the vapor enclosure.

\subsection{LA4000 TESTING PROCEDURE}

The operating procedure under lubricated conditions is explained by the following:

- The two wheels are thoroughly cleaned with acetone and then brought together.

- $\quad$ Power is supplied to wheel 11 (see Fig. 4).

- The desired load is applied at the end of the load arm.

- Before applying the desired angle of attack (AOA), the AOA should be dynamically set to zero first by maintaining zero lateral force on the computer monitor with the help of the LabTech software.

- Rotational speed can be controlled directly from the motor control box, with a maximum speed of $300 \mathrm{rpm}$.

- Lubricant is applied through the lubricant nozzle supplier (Fig. 5).

- Collecting the lateral-forces data versus time can be done by Labtech software to the desired number of cycles (or desired time).

- Collecting the volatile by-products of TOR lubricant is achieved with the adsorption tubes, while liquid (semivolatile) samples are collected manually in a container below the wheel contact area.

- After collecting volatile samples, the adsorption tubes must be kept at a very low temperature.

For more details about the testing procedure, the reader should refer to the LA4000 operating manual [15]. 


\subsection{FIELD PARAMETER SIMULATION}

The LA $4000^{\mathrm{TM}}$ simulates the following field conditions:

- The arm load range of 5 to $15 \mathrm{lb}$ in the lab simulates loads from a fully loaded railcar up to a locomotive. It should be noted

- The 300-rpm rotational speed in the lab simulates a speed in the field of 6 to $7 \mathrm{mph}$.

- The $1.7^{\circ}$ angle of attack is equivalent to the maximum lateral slip in the field of almost $3 \%$.

- The temperature range in the lab is from room temperature to $150^{\circ} \mathrm{F}$.

- Lubricant quantity can be dispensed precisely. 


\section{EXPERIMENTAL RESULTS AND DISSCUSSION}

\subsection{INTRODUCTION}

While the major focus of this project was on environmental effect, it was first necessary to define the range of test parameters of the experiment. To do this, several tests were performed to evaluate the lubricant consumption time as functions of angle of attack, axle load, and lubricant volume quantity.

\subsection{FRICTION/TIME RESULTS}

The first test series of this research focused on investigating the effects on lateral friction forces and consumption time of angle of attack (AOA), axle load, speed, and required lubricant quantity of TOR lubricant 483-98-6004. Consumption time for the lubricant is defined as the time needed for the lubricant to be consumed totally (i.e., when the measured lateral forces equal those of the base line for the unlubricated system).

\subsubsection{Effect of Angle of attack}

The AOA is a major parameters affecting friction and wear in the field, especially in dry environments [16]. In this test series, the load, rotational speed, and initial lubricant quantity was held constant and the AOA was varied to determine its impact on friction force and consumption time. The arm load was $5 \mathrm{lb}$, which simulates the stresses from a fully loaded rail-car. Rotational speed was held constant at $300 \mathrm{rpm}$ to simulating a train speed of 6 to $7 \mathrm{mph}$. TOR volume lubricant was $5 \mu \mathrm{L}$, and AOA was varied from $0.5^{\circ}$ to $1.7^{\circ}$. Three sets of experiments for AOAs of $0.5^{\circ}, 1.0^{\circ}$, and $1.7^{\circ}$ were performed in order to study the effect of AOA on lateral friction force and lubricant consumption time. The results show (see Fig. 6) that increases in AOA increase friction force and reduce the lubricant consumption time. The reason is that for higher AOA, there is more friction forces in the lateral direction, and will increase the shearing rate of the lubricant, which causes the lubricant to be consumed faster than when smaller angles are used. From Fig. 6, the consumption time versus AOA can be

calculated and plotted in Fig. 7, which indicates that consumption time is higher at smaller AOAs than at larger AOAs.

\subsubsection{Effect of Arm Load}

Another variable that affects lubricant consumption rate (and thus the rate at which it must be applied) is applied load. In this series of tests, the rotational speed was held constant at 300 rpm; 


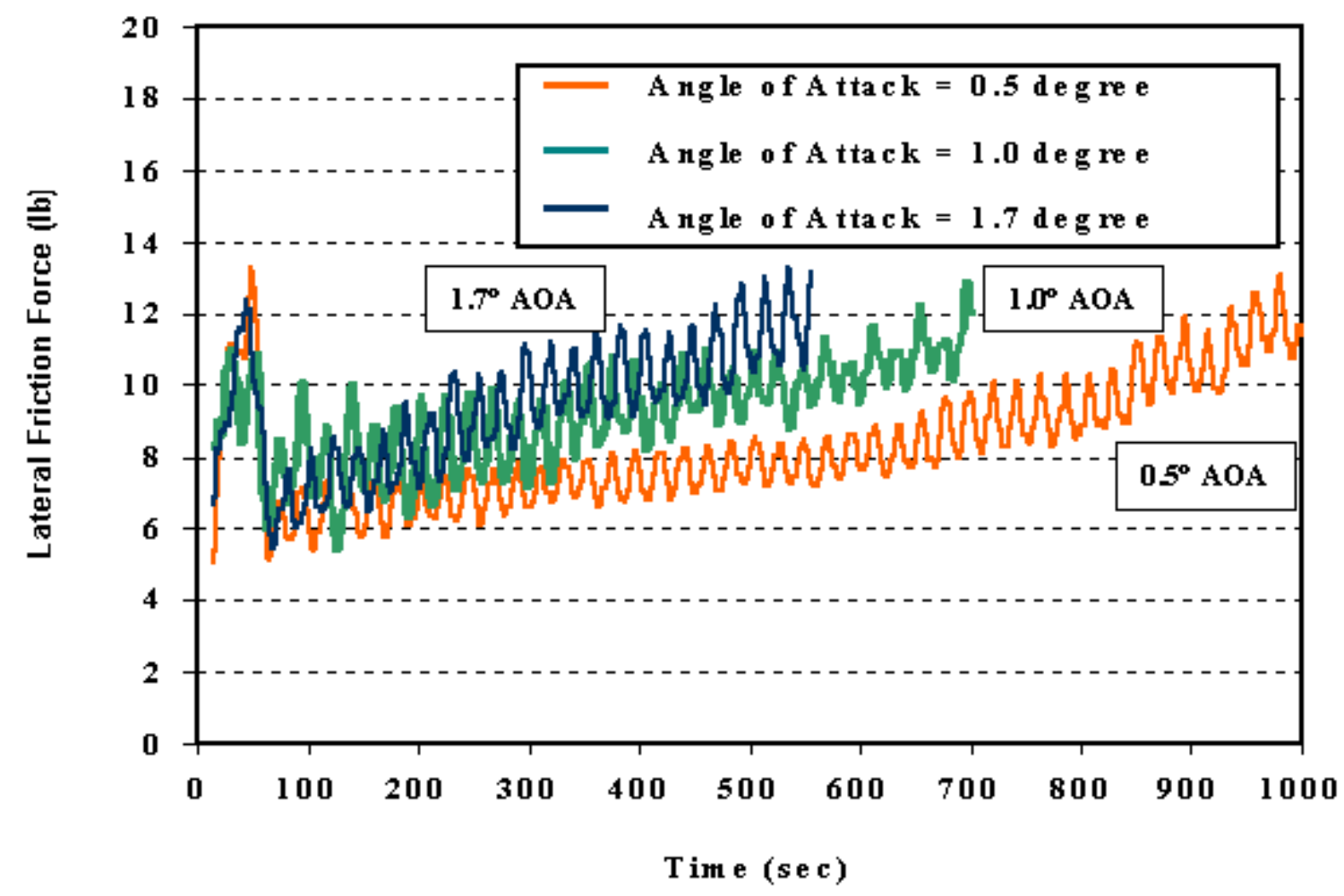

FIGURE 6 Effect of angle of attack on lateral friction forces and consumption time under TOR lubrication, for rotational speed of $300 \mathrm{rpm}$, room temp., $5 \mu \mathrm{L}$ of TOR lubricant, and arm load of $5 \mathrm{lb}$.

lubricant volume was maintained at $5 \mu \mathrm{L}$, and AOA was fixed at $1.7^{\circ}$. Applied loads were varied from 5 to $15 \mathrm{lb}$ on the loading weight L (see Fig. 4.), with the higher load simulating that of a locomotive. The results (Fig. 8) indicate that increasing the arm load increases the rate at which the lubricant is consumed.

\subsubsection{Effect of Lubricant Volume Quantity}

Volume of lubricant applied is also a critical parameter and, together with application, must be controlled to ensure that (a) a sufficient quantity is present to reduce lateral drag, and (b) the lubricant is consumed after the last wheel of the train passes over the rail. In this series of tests, applied load was held constant at $5 \mathrm{lb}$, rotational speed held constant at $300 \mathrm{rpm}$, and AOA maintained at $1.7^{\circ}$. The volume of lubricant applied (at the start of the test) ranged from 5 to $20 \mu \mathrm{L}$. The results of this series (Fig. 9) show that the more lubricant added between the wheel and the rail, the longer the time needed for the lubricant to be consumed totally. This suggests that the most efficient lubricant quantity must be calculated precisely according to many factors, such as number of cars, axle loads, train speed, and AOA. 


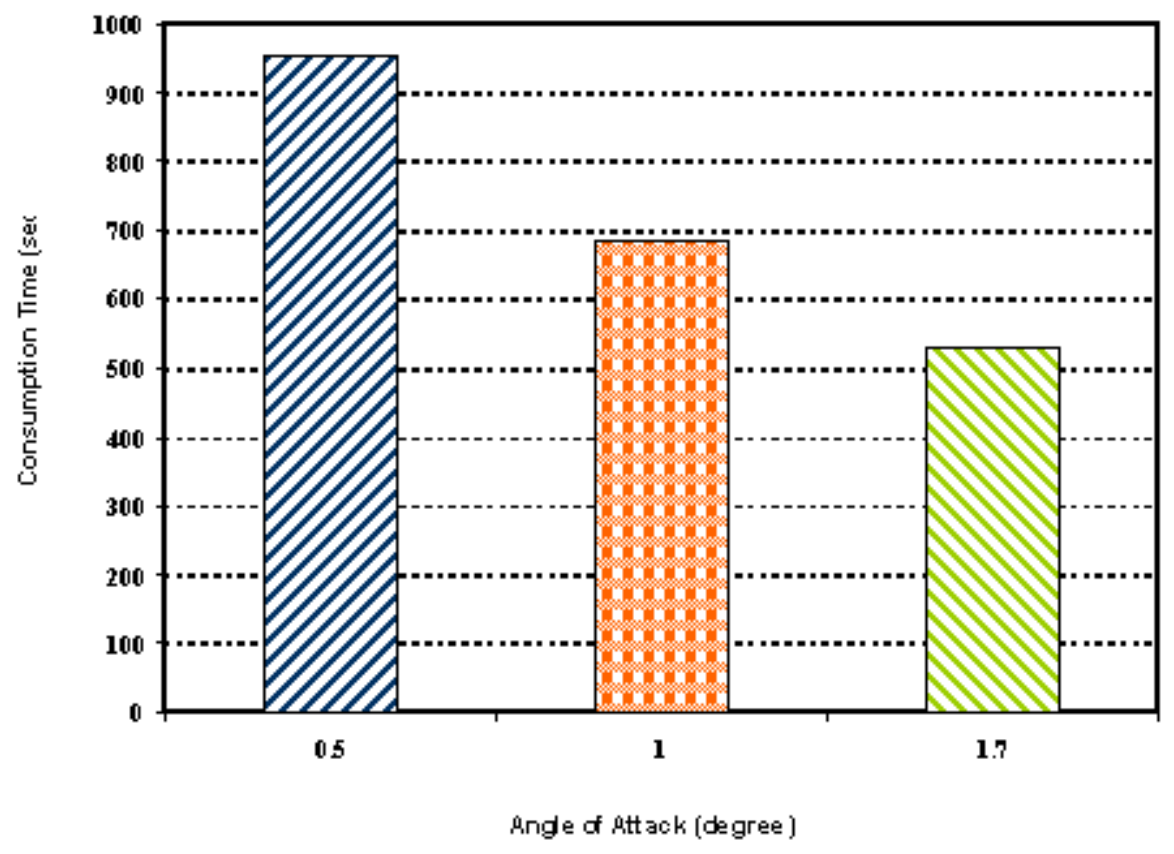

FIGURE 7 Effect of angle of attack on consumption time for TOR lubricant, for arm load $=5 \mathrm{lb}$, rotational speed $=300 \mathrm{rpm}$, room temp., and $5 \mu \mathrm{L}$ of TOR lubricant.

\subsection{BY-PRODUCT RESULTS}

As we have mentioned before that the primary goal for this project was the analysis of the volatile and semivolatile compounds produced from use of TOR lubrication and this will be discussed in more details as the following:

\subsubsection{Volatile Samples}

The volatile by-products produced from the TOR lubricant were collected by special adsorption tubes (Fig. 5). The tubes were sent to the Analytical Chemistry Laboratory at Argonne National Laboratory for GC/MS analysis. 


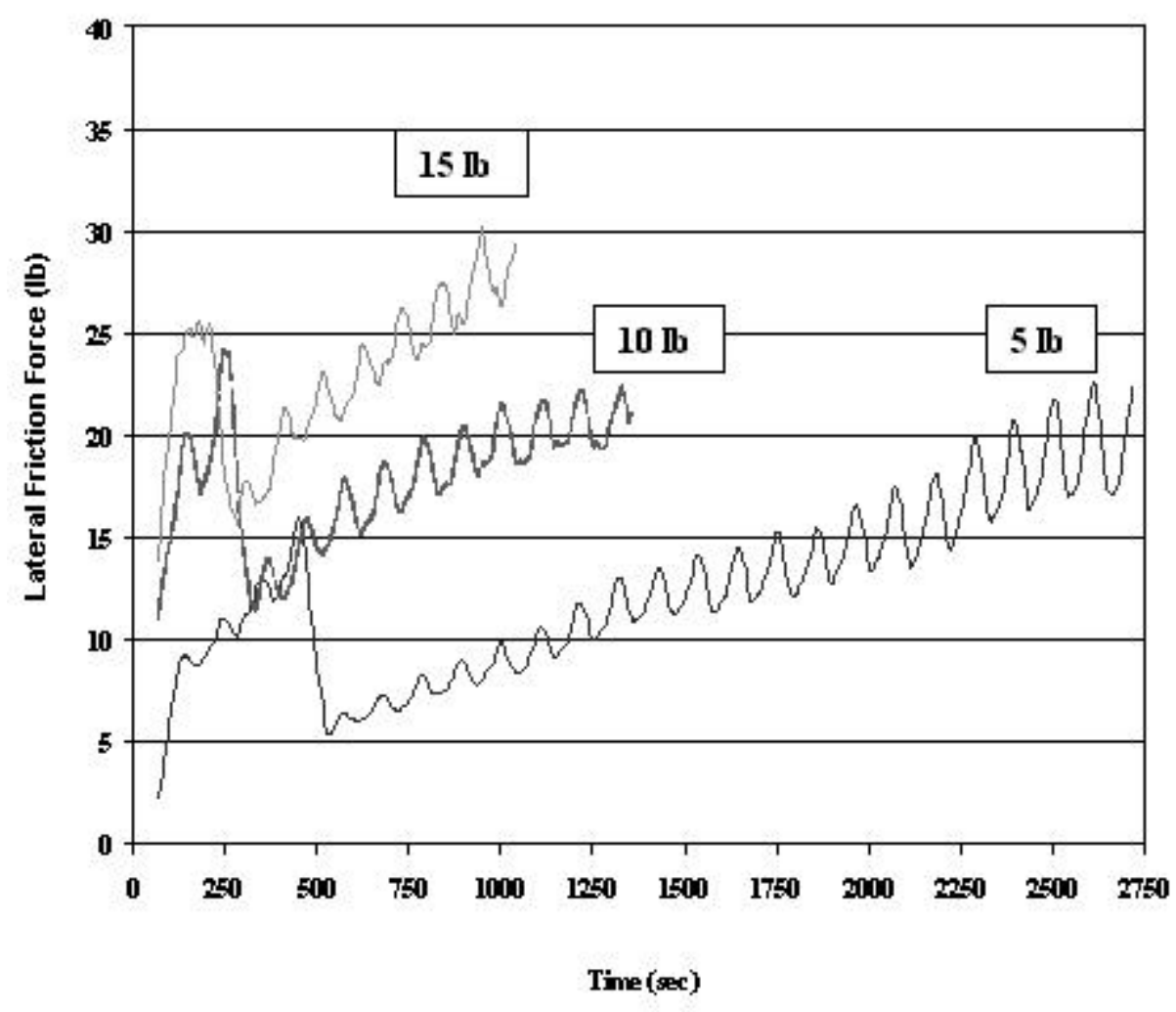

FIGURE 8 Effect of arm load on lateral friction force and consumption time under TOR lubrication, for rotational speed of 300 rpm, room temp., and $5 \mu \mathrm{L}$ of TOR lubricant.

Experiment and Test Conditions. To identify the source of the analytes as either from the room or the TOR lubricant itself, five experiments with differing conditions were conducted according to the following run numbers:

1. Dry collection of room air with no wheel rotation (no lubricant used). In this configuration, the benchtop test rig was turned off, and the gas collection rig ran for a period of $5 \mathrm{hr}$ at flow rates of $0.75 \mathrm{~L} / \mathrm{min}$.

2. Dry collection of the enclosure with wheel rotation and $0^{\circ} \mathrm{AOA}$ and no lubricant. In this configuration, the benchtop rig was run under a load of $5 \mathrm{lb}$, which simulates the load of a locomotive, at a rotational speed of $300 \mathrm{rpm}$, for $5 \mathrm{hr}$ at an AOA of $0^{\circ}$, without TOR lubricant.

3. This run was the same as run 2 except that AOA was $1.7^{\circ}$. 


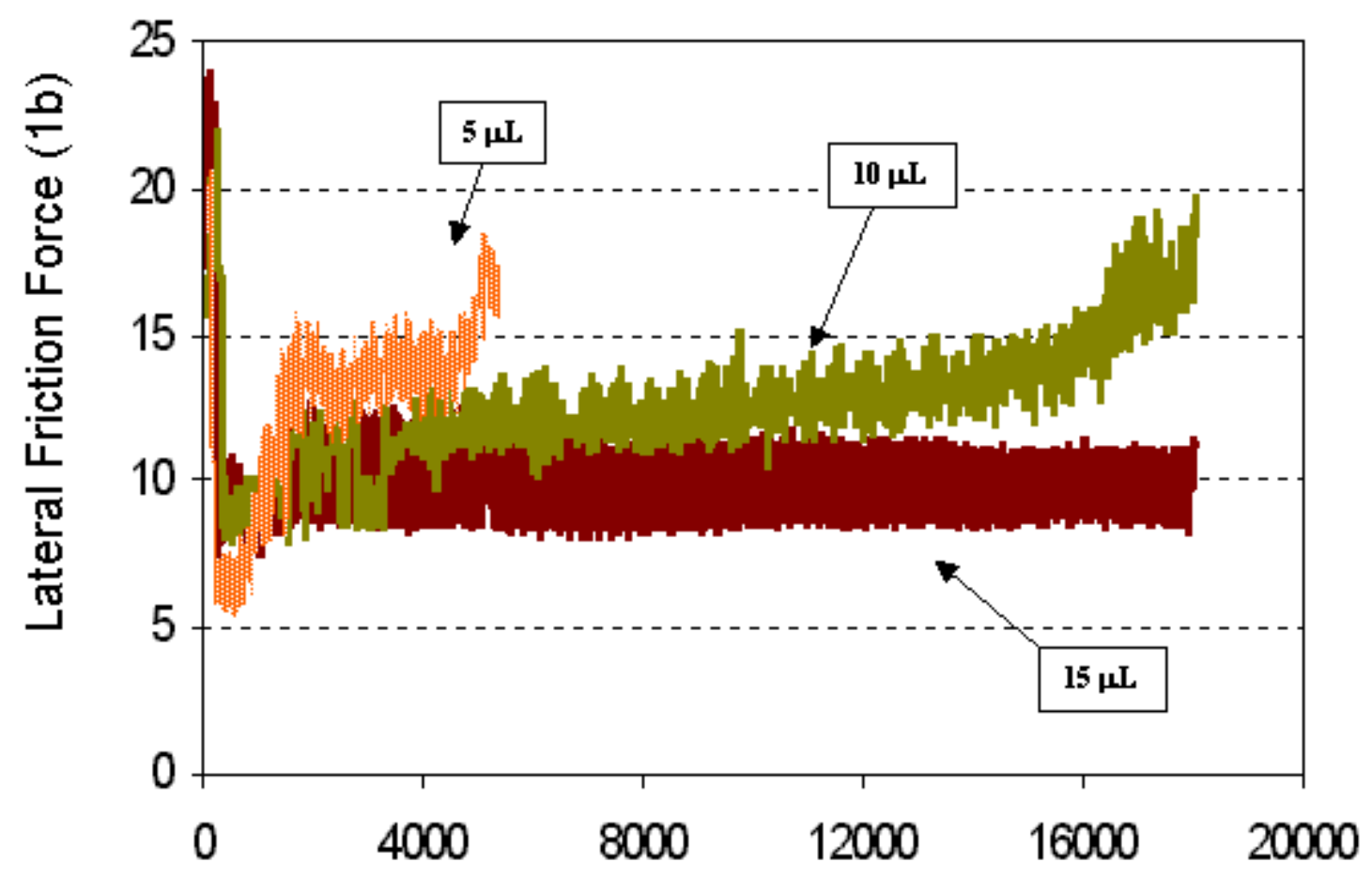

Time (sec)

FIGURE 9 Effect of lubricant quantity on lateral friction forces and consumption time, for arm load of $5 \mathrm{lb}$, room temp., and $1.7^{\circ}$ angle of attack.

4. In this run, TOR lubricant was added with wheel rotation of $300 \mathrm{rpm}, 5 \mathrm{lb}$ arm load, and $0^{\circ}$ AOA. This is a duplicate of condition 2 with the exception that TOR lubricant was applied at a rate of $75 \mu \mathrm{L} / \mathrm{min}$ for a total of $3.33 \mathrm{~min}$. The total amount of TOR used was $0.25 \mathrm{~mL}$.

5. Top-of-rail lubricant was added with wheel rotation of $300 \mathrm{rpm}, 5 \mathrm{lb}$ normal force, and $1.7^{\circ}$ AOA. TOR lubricant was applied at a rate of $75 \mu \mathrm{L} / \mathrm{min}$ for a total of $3.33 \mathrm{~min}$. Total TOR used was $0.25 \mathrm{~mL}$ for $5 \mathrm{hr}$.

Friction/Time Series Results. Figure 10 shows lateral friction forces versus time for Run 2, 3, and 5 for a period of $5 \mathrm{hr}$. Run $2\left(0^{\circ} \mathrm{AOA}\right)$ shows no lateral friction forces, unlike that of Run $3\left(1.7^{\circ}\right.$ AOA). The figure also shows that when TOR lubricant was used, there is a reduction in lateral friction force of nearly $60 \%$ compared to when no lubricant was used. 


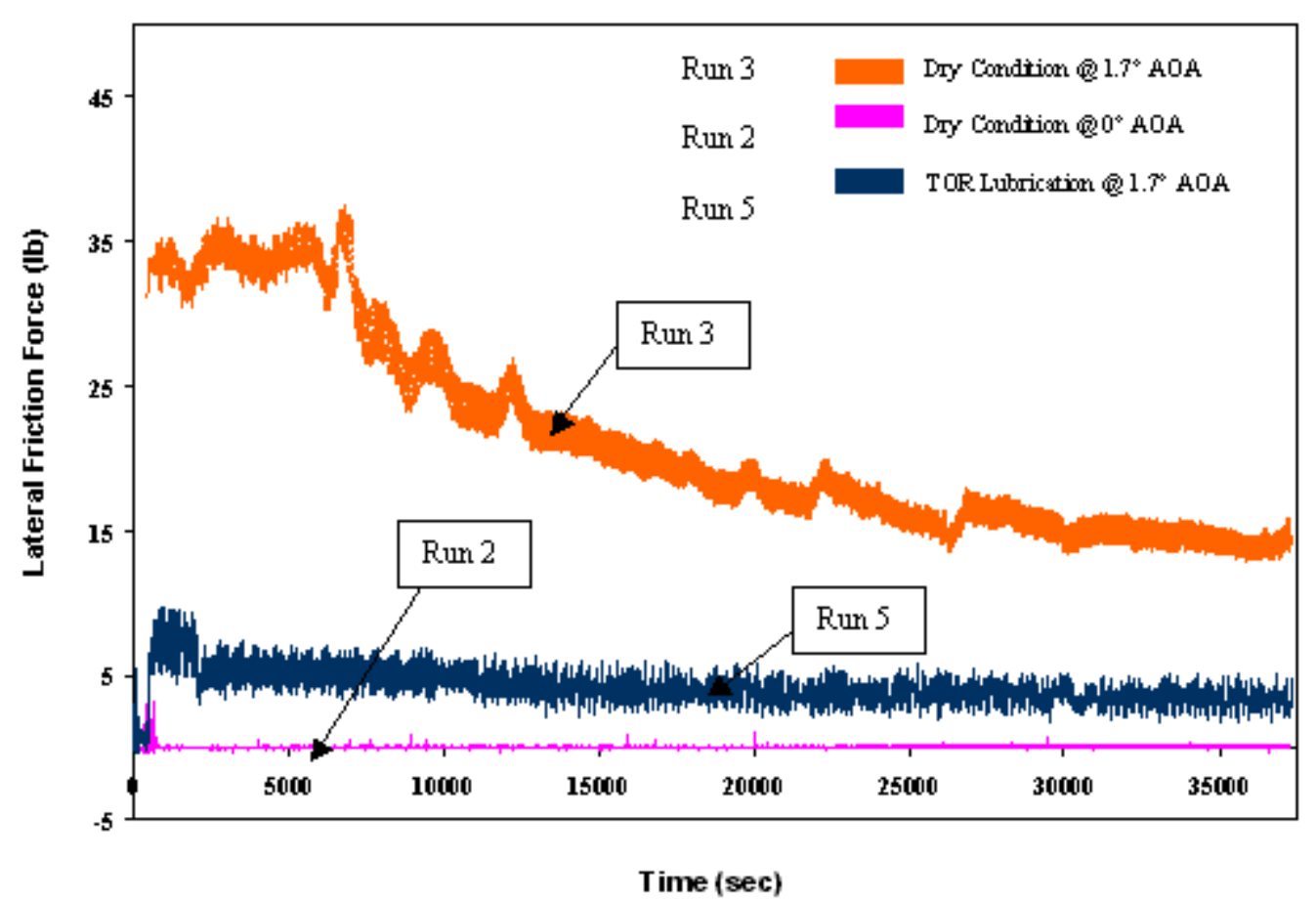

FIGURE 10 Friction-time results for runs 2, 3, and 5 for arm load $5 \mathrm{lb}$, $300 \mathrm{rpm}$, period of $5 \mathrm{hr}$, room temp., and total of $0.25 \mathrm{~mL}$ TOR lubricant.

Volatile By-Product Analysis. The process of by-product analysis involves passing ultraclean bottled air through the interaction zone to transport volatile by-products to a Tenax trap. The apparatus for collecting the gas samples is essentially a small Plexiglas enclosure surrounding the two contacting wheels (see Fig. 5). Two adsorption tubes (Tenax traps) are used in series for collecting the volatile organic compounds. The traps are then sealed for subsequent analysis of the trapped compounds by GC/MS.

After each run, the sealed Tenax traps containing the trapped material were sent to Argonne's Analytical Chemistry Laboratory for GC/MS analysis. The gaseous analytes were qualitatively determined by GC/MS after adsorption from the Tenax traps by heating the traps at $190^{\circ} \mathrm{C}$ for 3 min while flowing $\mathrm{He}$ at $20 \mathrm{~mL} / \mathrm{min}$ through the trap. Figures 11-15 show the GC/MS of the total ion chromatograms for the five runs. A number of peaks were observed, and these are listed in Table 1 for the five different runs described above. For comparison, Table 2 lists the 43 compounds that are on the Resource Conservation and Recovery Act (RCRA) list of volatile compounds the US EPA regulates in terms of disposal. 


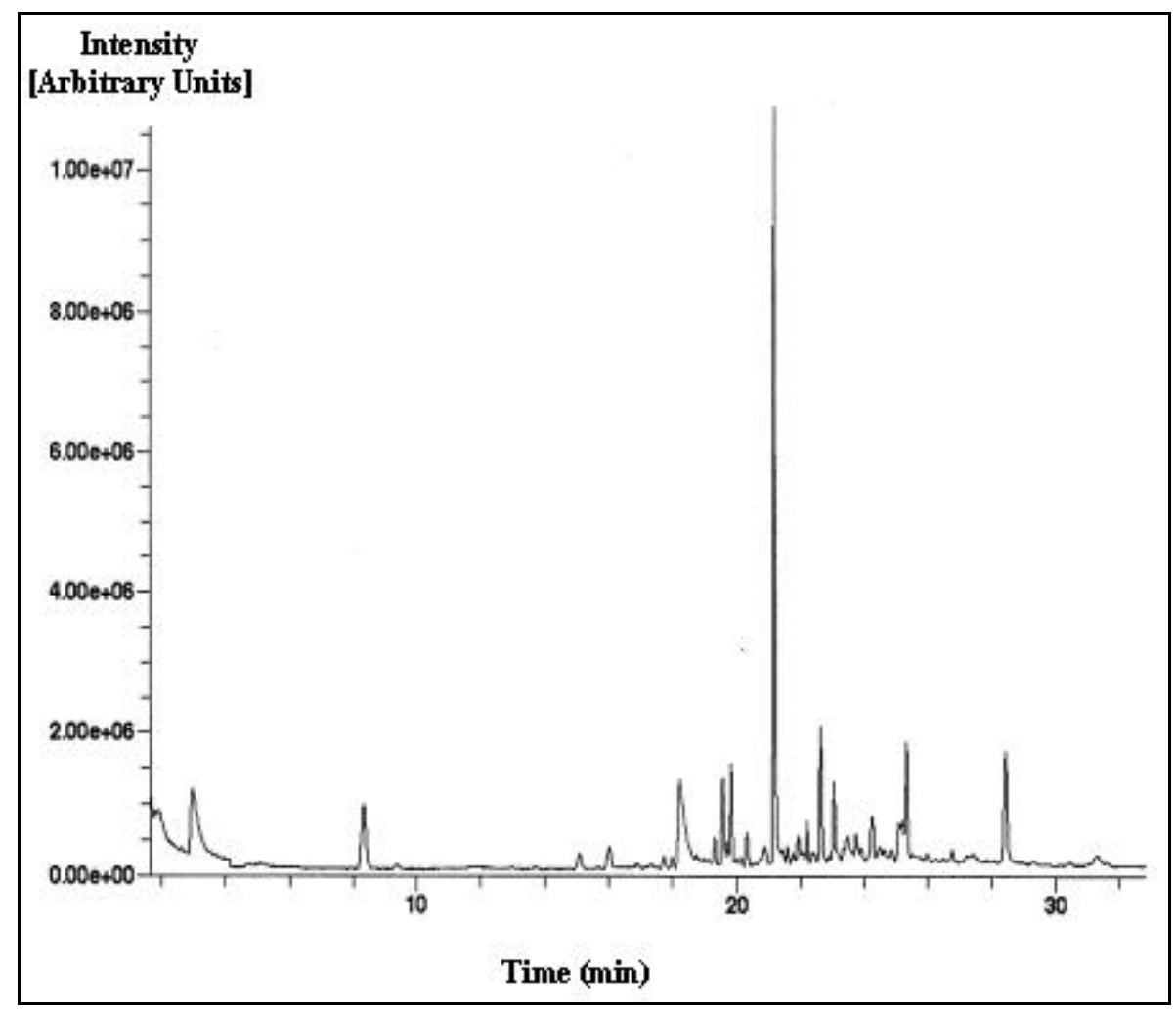

FIGURE 11 GC/MS intensity versus time for volatile Run 1, room sampling, and no motion.

A comparison of these two tables indicates that 1,2-dichloroethane and acetone, which are considered toxic, are common in both tables. Analysis of Table 1 also indicates that these two compounds were observed in the "dry" runs in which the TOR lubricant was not applied. This suggests that the source of these two compounds was not the TOR lubricant, but rather the room environment where the samples were collected (acetone is indeed used routinely in the surrounding lab space to clean and degrease samples and may have been used to clean the wheels before the tests). The source of the 1,2 dichloroethane is not as evident, but because it is also present in the dry run tests at the same relative level, it may not be of concern. It should be mentioned here that this a qualitative analysis. For quantitative analysis, a known volume of ultra-clean air should be controlled and precisely measured while collecting the volatile sample. This would allow us to find the relative composition of the analytes precisely.

\subsubsection{Semivolatile Samples}

A liquid sample of the TOR lubricant was collected manually by placing an empty container below the wheel area. Because the collected sample was too small after only one 


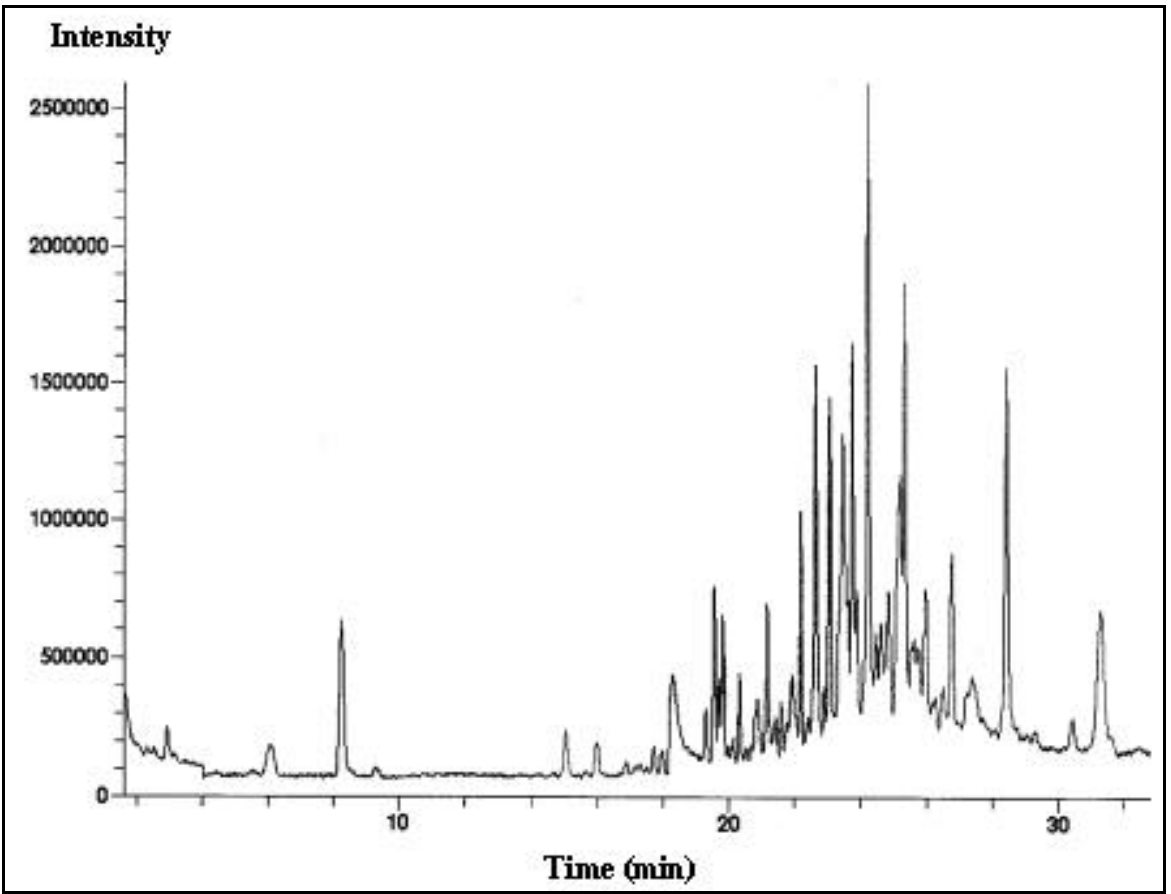

FIGURE 12 GC/MS intensity versus time for volatile Run 2, dry contact, $0^{\circ}$ AOA, and motion.

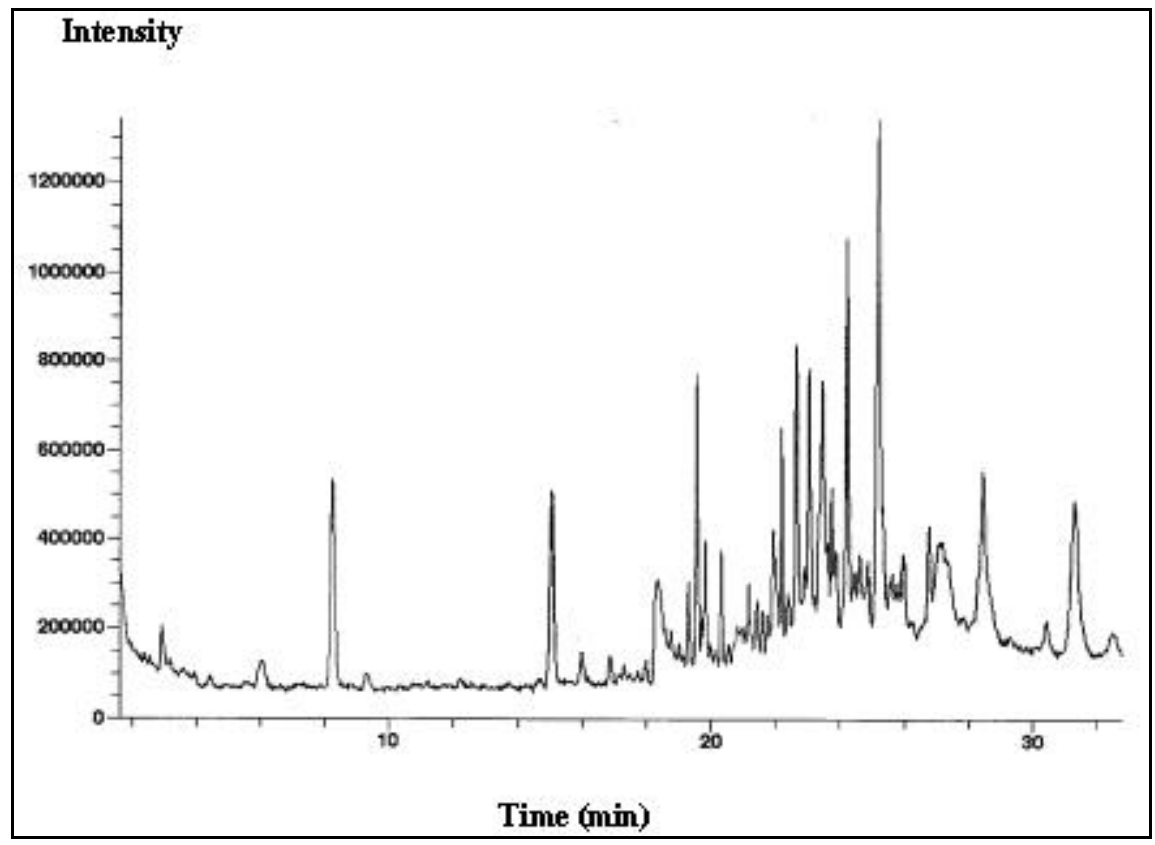

FIGURE 13 GC/MS intensity versus time for volatile Run 3, dry contact, $1.7^{\circ} \mathrm{AOA}$, and motion. 


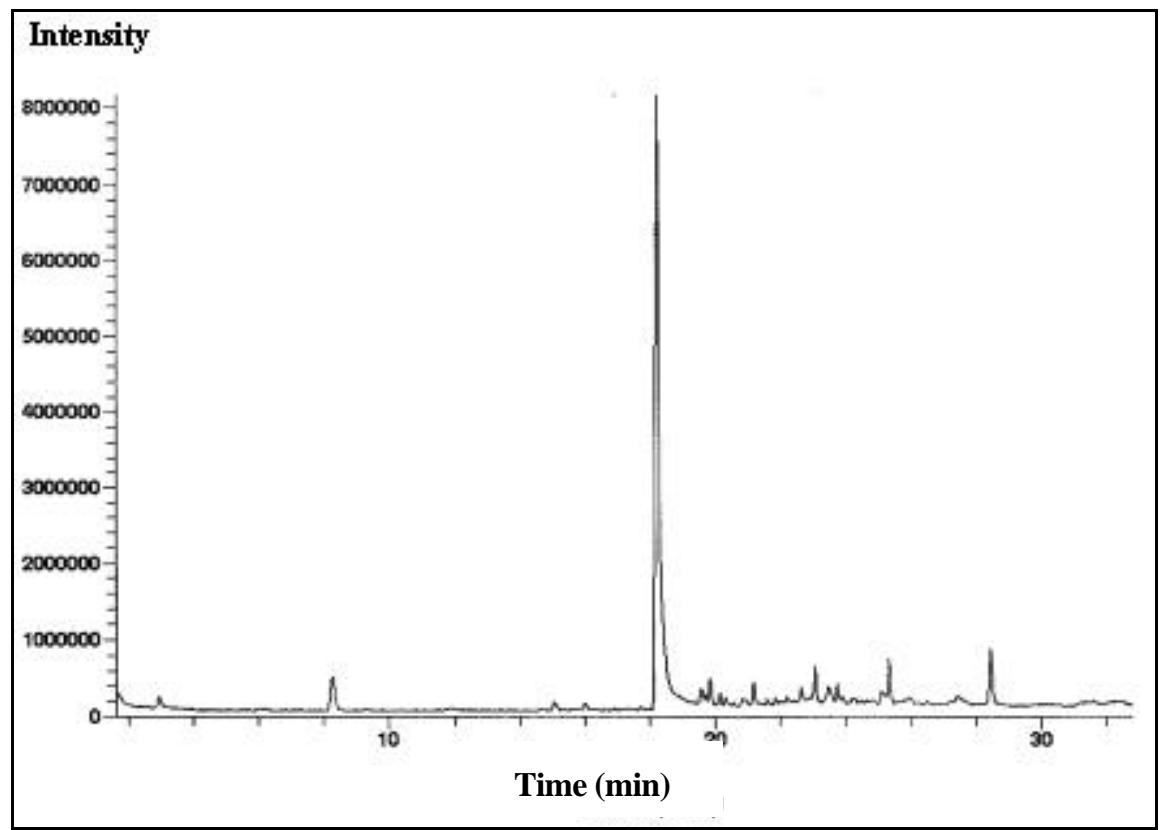

FIGURE 14 GC/MS intensity versus time for volatile Run 4, TOR lubrication, ${ }^{\circ}$ AOA, and motion.

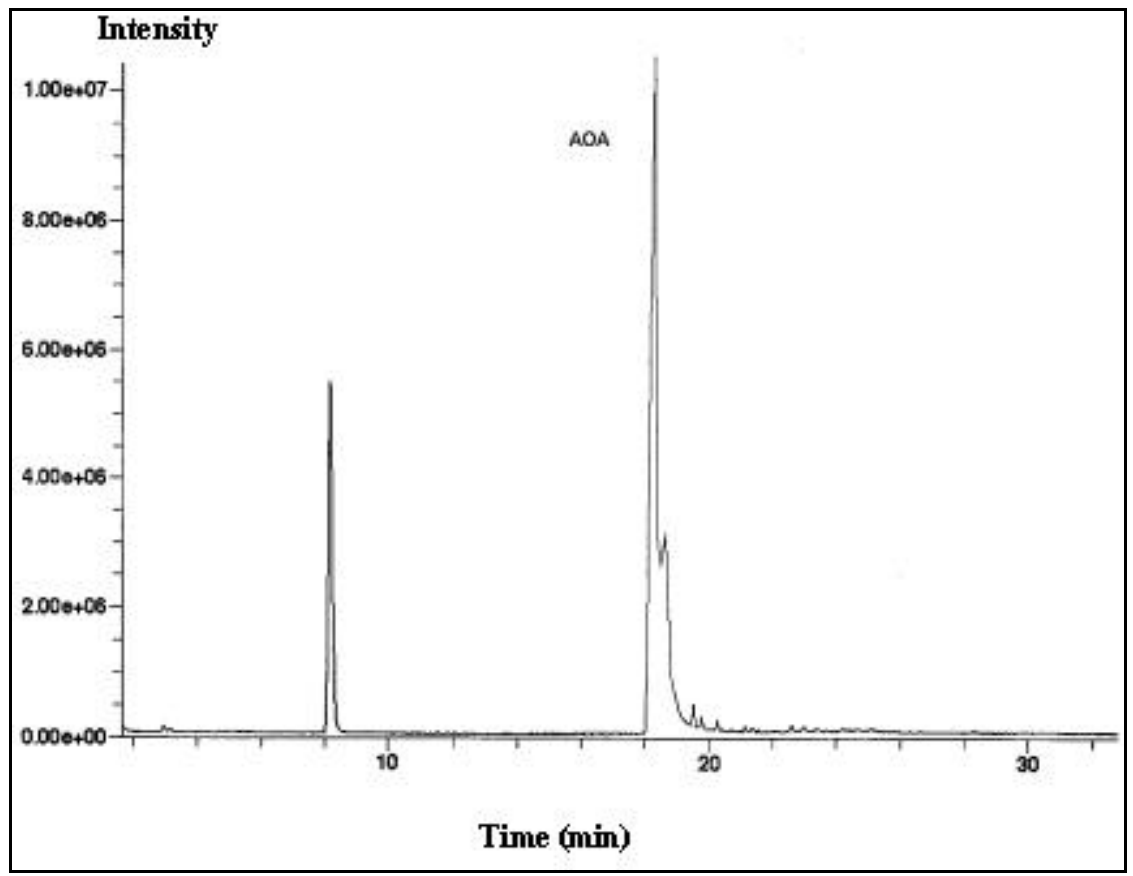

FIGURE 15 GC/MS intensity versus time for volatile Run 5, TOR lubrication, $1.7^{\circ} \mathrm{AOA}$, and motion. 
TABLE 1 Relative composition of analytes in collected gas

\begin{tabular}{|c|c|c|c|c|c|}
\hline Experiment Number & 1 (Dry) & 2 (Dry) & 3 (Dry) & 4 (Lubricant) & 5 (Lubricant) \\
\hline Test Conditions & $\begin{array}{c}\text { No } \\
\text { Motion }\end{array}$ & $\begin{array}{c}\text { With } \\
\text { Motion } \\
0^{\circ} \mathbf{A O A}\end{array}$ & \begin{tabular}{|c|} 
With \\
Motion \\
$1.7^{\circ} \mathbf{A O A}$ \\
\end{tabular} & $\begin{array}{c}\text { With Motion } \\
0^{\circ} \text { AOA }\end{array}$ & $\begin{array}{c}\text { With Motion } \\
1.7^{\circ} \mathbf{A O A}\end{array}$ \\
\hline Compound $\triangleright$ & $\operatorname{Rel} \%$ & Rel \% & Rel \% & $\operatorname{Rel} \%$ & Rel \% \\
\hline Acetone & 8.3 & 0.5 & 0.0 & 0.5 & 1.0 \\
\hline 1,2-dichloroethane & 4.9 & 3.5 & 5.5 & 3.1 & 4.3 \\
\hline toluene & 1.1 & 1.0 & 5.2 & 0.0 & 0.0 \\
\hline octane & 1.3 & 0.7 & 0.0 & 0.7 & 0.0 \\
\hline 1,2-propanediol $\Rightarrow$ & 10.9 & 3.5 & 5.4 & 38.6 & 72.2 \\
\hline ethylbenzene & 1.4 & 0.6 & 1.3 & 0.1 & 0.2 \\
\hline 1,2-dimethylbenzene & 3.4 & 2.0 & 4.1 & 1.9 & 1.2 \\
\hline nonane & 3.7 & 1.7 & 1.8 & 2.0 & 1.6 \\
\hline 1,4-dimethylbenzene & 1.1 & 1.1 & 1.5 & 0.8 & 0.8 \\
\hline 2-butoxyethanol & 25.7 & 2.1 & 1.2 & 1.3 & 0.0 \\
\hline not identified & 0.8 & 0.7 & 1.0 & 0.7 & 0.0 \\
\hline not identified & 0.7 & 0.6 & 3.2 & 0.7 & 0.0 \\
\hline not identified & 1.3 & 2.2 & 0.0 & 1.2 & 1.5 \\
\hline decane & 1.3 & 2.3 & 2.6 & 1.4 & 0.0 \\
\hline benzaldehyde & 5.3 & 6.1 & 5.9 & 2.9 & 2.0 \\
\hline C-10 alkane & 3.2 & 4.4 & 4.8 & 3.8 & 3.0 \\
\hline C-10 alkane & 2.1 & 8.6 & 7.6 & 3.0 & 0.0 \\
\hline not identified & 2.1 & 1.4 & 1.1 & 0.5 & 0.0 \\
\hline 2-ethyl-1-hexanol & 1.1 & 5.3 & 2.3 & 1.2 & 0.0 \\
\hline undecane & 2.6 & 11.0 & 7.1 & 4.1 & 2.9 \\
\hline not identified & 0.6 & 2.2 & 1.6 & 0.0 & 0.0 \\
\hline not identified & 0.6 & 3.6 & 1.5 & 1.4 & 1.5 \\
\hline not identified & 1.6 & 0.0 & 12.8 & 6.6 & 0.4 \\
\hline Benzeneacetic acid, a-4-TMS & 1.9 & 6.6 & 1.0 & 0.0 & 0.0 \\
\hline nonanal & 5.1 & 6.9 & 0.0 & 3.0 & 2.3 \\
\hline not identified & 0.0 & 1.4 & 0.0 & 0.0 & 0.0 \\
\hline not identified & 0.0 & 2.9 & 0.0 & 0.0 & 0.0 \\
\hline not identified & 0.6 & 2.7 & 0.0 & 0.9 & 0.0 \\
\hline not identified & 0.0 & 0.0 & 1.8 & 1.0 & 0.0 \\
\hline 3,5,5-trimethylhexanoic acid & 0.0 & 2.0 & 2.9 & 9.6 & 0.0 \\
\hline not identified & 0.0 & 0.0 & 2.4 & 0.0 & 0.0 \\
\hline decanal & 6.5 & 6.9 & 6.9 & 4.0 & 5.1 \\
\hline not identified & 0.0 & 0.8 & 0.0 & 0.0 & 0.0 \\
\hline substituted 1,3-dioxane & 0.8 & 4.6 & 7.5 & 5.3 & 0.0 \\
\hline Total \% & 100.0 & 100.0 & 100.0 & 100.0 & 100.0 \\
\hline
\end{tabular}

$\Rightarrow$ Toxic compounds are listed in bold type.

-1,2-propanediol is nontoxic and is the major compound of the TOR lubricant. 
TABLE 2 Target Compound List (TCL)

\begin{tabular}{|c|c|}
\hline Compound & Compound \\
\hline Acetone & 1,1-dichloropropene \\
\hline Dichlorodifluoromethane & Chloromethane \\
\hline Vinyl Chloride & Bromomethane \\
\hline Chloroethane & Trichlorofluoromethane \\
\hline 1,1-Dichloroethene & Methylene Chloride \\
\hline 1,2-Dichloroethene & 1,1-Dichloroethane \\
\hline 2,2-Dichloroethene & Bromochloromethane \\
\hline Chloroform & 1,1-Trichloroethane \\
\hline Carbon Tetrachloride & Bromodichloromethane \\
\hline Benzene & 1,2-Dichloroethane \\
\hline Cis-1,3-Dichloropropene & Toluene \\
\hline Trichloroethene & 1,2-Dichloropropane \\
\hline Trans-1,3-Dichloropropene & 1,1,2-Trichloroethane \\
\hline Tetrachloroethene & 1,3-Dichloropropane \\
\hline Dibromochloromethane & Chlorobenzene \\
\hline 1,1,1,2-Tetrachloroethane & Ethyl benzene \\
\hline m-Xylene & p-Xylene \\
\hline o-Xylene & Styrene \\
\hline Bromoform & Isopropylbenzene \\
\hline Bromobenzene & $1,1,2,2$-Tetrachloroethane \\
\hline 1,2,3-Trichloropropane & n-propylbenzene \\
\hline 2-Chlorotoluene & 4-Chlorotoluene \\
\hline $1,3,5$-Trimethylbenzene & tert-Butylbenzene \\
\hline 1,2,4-Trimethylbenzene & sec-Butylbenzene \\
\hline 1,3-Dichlorobenzene & 1,4-Dichlorobenzene \\
\hline p-Isopropyltoluene & 1,2-Dichlorobenzene \\
\hline n-Butylbenzene & 1,2-Dibromo-3-chloropropane \\
\hline 1,2,4-Trichlorobenzene & Hexachlorobutadiene \\
\hline Naphthalene & 1,2,3-Trichlorobenzene \\
\hline
\end{tabular}

experiment, collection was continued during several experiments (i.e., 20 hr). For comparison, the composition of the TOR lubricant was analyzed before and after its use. Tables 3 and 4 show the compositions of the lubricant before and after use, respectively. For comparison, Table 5 gives the target compound list (TCL) of compounds that are on the RCRA priority pollutant list of US EPA.

Comparing the results in Tables 3 and 4 with the compounds in Table 5, we see that the TOR lubricant, before and after use, contains none of the TCL compounds considered hazardous by the EPA. Also, comparing Tables 2 and 3 shows no difference between the compounds before and after use of the lubricant, except for 1-ethylene glycol, diformate, and 5-methoxy-1-pentanol. 
TABLE 3 Composition of TOR Lubricant 483-98-6004 before use

\begin{tabular}{lcl}
\hline Retention Time (min) & Composition $(\%)$ & \multicolumn{1}{c}{ Tentatively Identified Compound } \\
\hline $5.0-9.0$ & 97.7 & 1,2 - Propanediol \\
12.7 & 0.3 & $1,1^{\prime}-$ Oxybis -2 - propanol \\
$13.2-14.0$ & 0.4 & $2-(2-$ Aminoethanol ) Amino ethanol \\
14.8 & 0.7 & Unknown \\
$15.6-15.9$ & 0.5 & $3,5,5-$ Trimethyl hexanoic acid \\
$16.5-19.0$ & 0.4 & $\mathrm{C}_{7}-\mathrm{C}_{10}$ Alkyl acid methyl/ethyl ester \\
\hline
\end{tabular}

TABLE 4 Composition of TOR Lubricant 483-98-6004 after use

\begin{tabular}{lrl}
\hline & & \\
Retention Time $(\mathrm{min})$ & Composition $(\%)$ & Tentatively Identified Compound \\
\hline & & \\
$6.0-6.0$ & 64.7 & 1,2 - Propanediol \\
8.145 & 0.8 & 1-Ethylene glycol, diformate \\
9.119 & 1.1 & 5 - Methoxy - 1 -pentanol \\
12.085 & 0.9 & Unknown \\
$15.099-15.913$ & 1.3 & 1,1 ' - Oxybis - 2 - propanol \\
17.769 & 20.0 & $3,5,5$ - Trimethylhexanoic acid \\
17.868 & 2.4 & Unknown \\
$18.358-18.643$ & 2.5 & Unknown \\
\hline
\end{tabular}

TABLE 5 Target Compound List (TCL)

\begin{tabular}{|c|c|c|}
\hline Compound & Compound & Compound \\
\hline N-Nitrosodimethylamine & N-Nitrosodibutylamine & 1,2-Diphenylhydrazine \\
\hline 2-Picoline & 4-Chloro-3-methylphenol & 4-Bromophenyl phenyl ether \\
\hline Methyl methansulfonate & 2-Methylnaphthalene & Phenacetin \\
\hline Ethyl methansulfonate & 1,2,4,5-Tetrachlorobenzene & Hexachlorobenzene \\
\hline Aniline & Hexachlorocyclopentadiene & 4-Aminobiphenyl \\
\hline Phenol 2,4,6 & Trichlorophenol & Benzidine \\
\hline bis(2-Chloroethyl)ether & 2,4,5-Trichlorophenol & Pentachlorophenol \\
\hline 2-Chlorophenol & 2-Chloronaphthalene & Pentachloronitrobenzene \\
\hline 1,3-Dichlorobenzene & 1-Chloronaphthalene & Phenanthrene \\
\hline 1,4-Dichlorobenzene & 2-Nitroaniline & Pronamide \\
\hline Benzyl alcohol & Acenaphthylene & Anthracene \\
\hline 1,2-Dichlorobenzene & Dimethyl phthalate & Di-n-butylphthalate \\
\hline 2-Methylphenol & 2,6-Dinitrotoluene & Fluoranthene \\
\hline bis(2-Chloroisopropyl)ether & 2,4-Dinitrotoluene & Pyrene \\
\hline Acetophenone & 3-Nitroaniline & p-Dimethylaminoazobenzene \\
\hline
\end{tabular}


TABLE 5 (Cont.)

\begin{tabular}{lll}
\hline \multicolumn{1}{c}{ Compound } & \multicolumn{1}{c}{ Compound } & \multicolumn{1}{c}{ Compound } \\
\hline & & \\
Hexachloroethane & Acenaphthene & Butylbenzylphthalate \\
N-nitroso-di-n-propylamine & 2,4-Dinitrophenol & Benzo (a) anthracene \\
4-Methylphenol & Dibenzofuran & 3,3'-Dichlorobenidine \\
Nitrobenzene & Pentachlorobenzene & Chrysene \\
N-Nitrosopiperidine & 4-Nitrophenol & bis(2-ethylhexyl)phthalate \\
Isophorone & 2-Naphthylamine & Di-n-octylphthalate \\
2-Nitrophenol & 1-Naphthylamine & Benzo(b)fluoranthene \\
2,4-Dimethyphenol & 2,3,4,6-Tetrachlorophenol & 7,12-Dimethylbenz(a)anthracene \\
2,4-Dichlorophenol & 4-Chlorophenol phenyl ether & Benzo(a)pyrene \\
Benzoic acid & Diethylphthalate & 3-Methylcholanthrene \\
1,2,4-Trichlorobenzene & 4-Nitroaniline & Dibenz(a,j)acridine \\
Naphthalene & 4,6-Dinitro-2-methylphenol & Ideno(1,2,3-cd)pyrene \\
4-Chloraniline & a,a-Dimethylphenethylamine & Dibenzo(a,h)anthracene \\
bis(2-Chloroethoxy)methane & Fluorene & Benzo(k)fluoranthene \\
\hline
\end{tabular}

Again, these two compounds are not on the US EPA priority pollutant list. The unknown compounds could not be identified because they were not target analytes and additional data would be needed for their identification. Also, Figures 16 and 17 show GC/MS total ion chromatogram corresponding to data in Tables 3 and 4 for the semivolatile samples of the TOR lubricant before and after use, respectively.

Figure 16 shows that the compound with the highest relative percentage in the semivolatile sample from the TOR lubricant before use is 1,2-propanediol, which is the major composition of the TOR lubricant itself, and then 4-hydroxy-4-methyl-2-pentanone which is also present in the solvent used for dissolving the semivolatile sample. Figure 17 is similar to Fig. 16, except that the 1,2-propanediol composition here is relatively lower in percentage than that in Fig. 16. Figure 18 shows comparison of mass spectrum of 1,2 propanediol from the sample with the standard from the computerized library spectra (Fig. 17). 


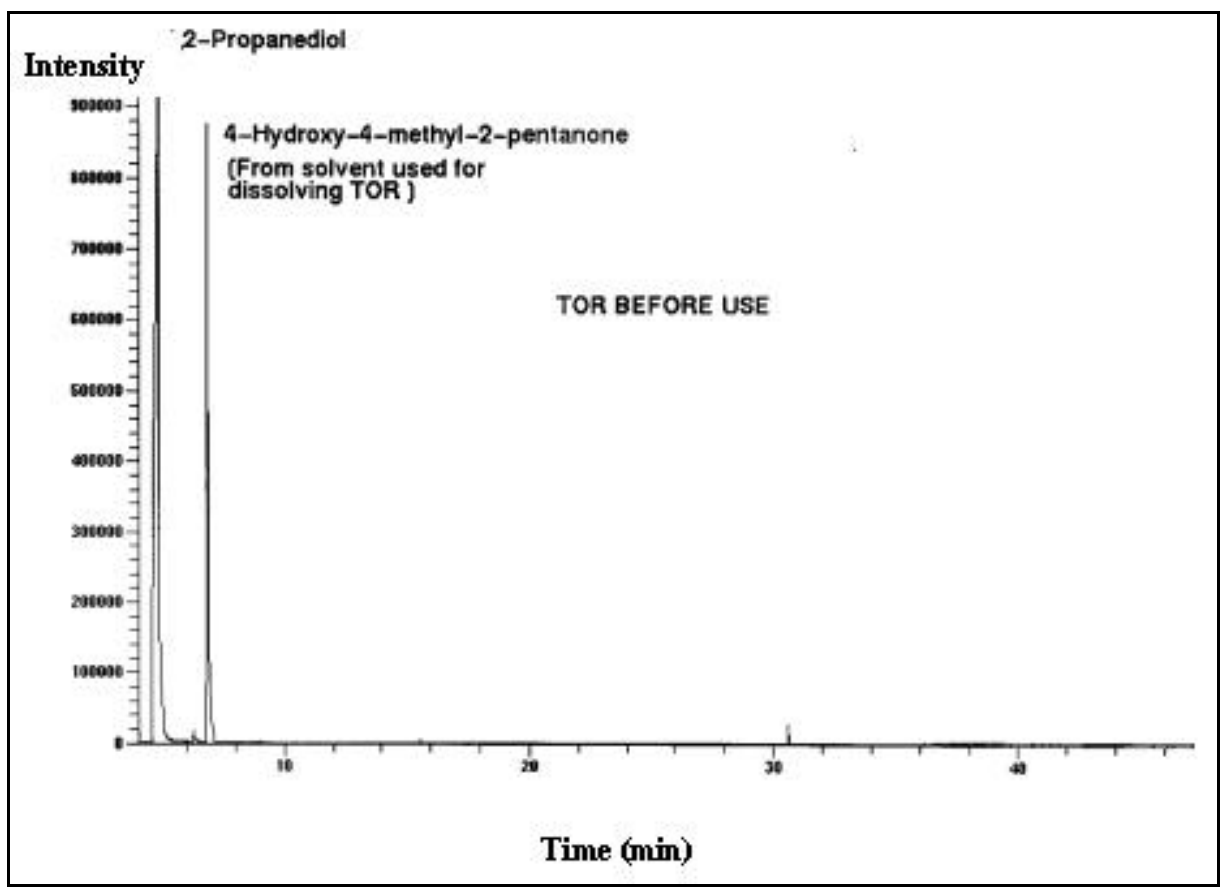

FIGURE 16 GC/MS intensity versus time for semivolatile of TOR lubricant before use.

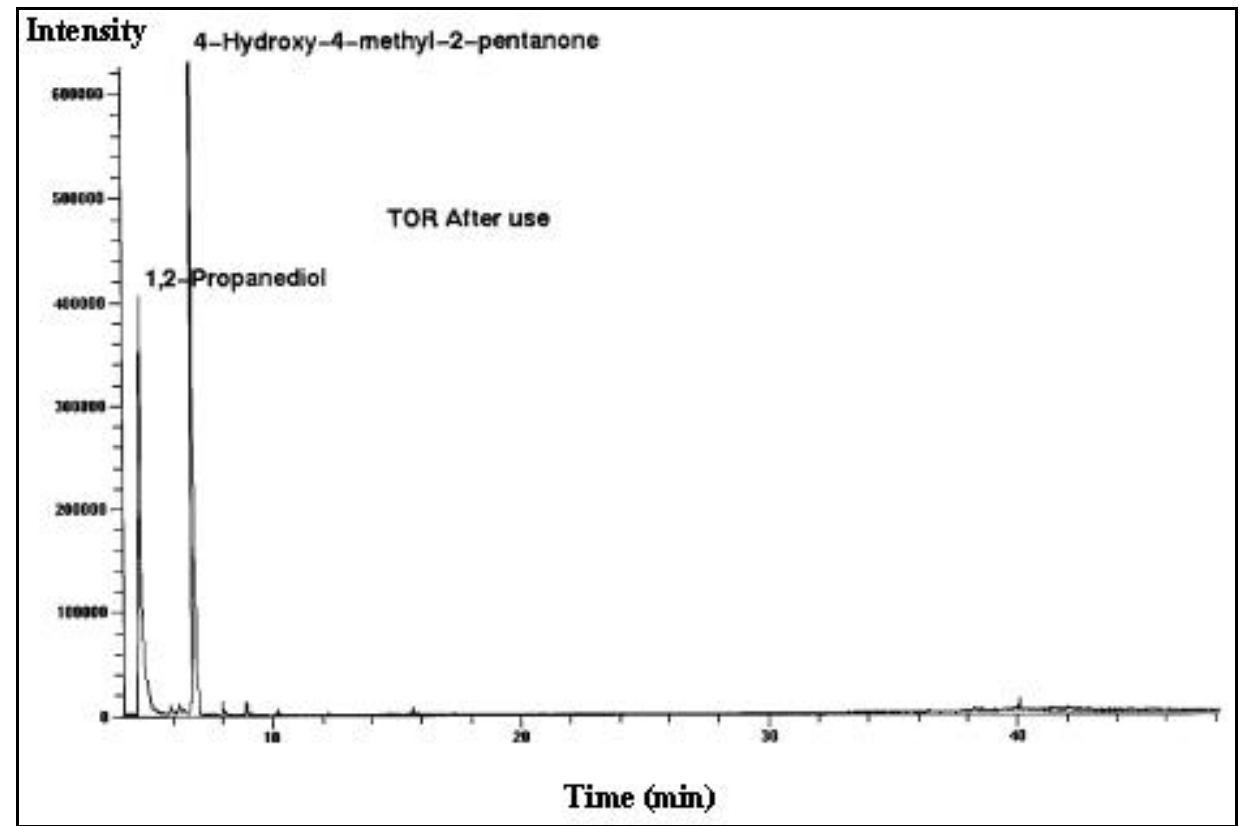

FIGURE 17 GC/MS intensity versus time for semivolatile of TOR lubricant after use. 


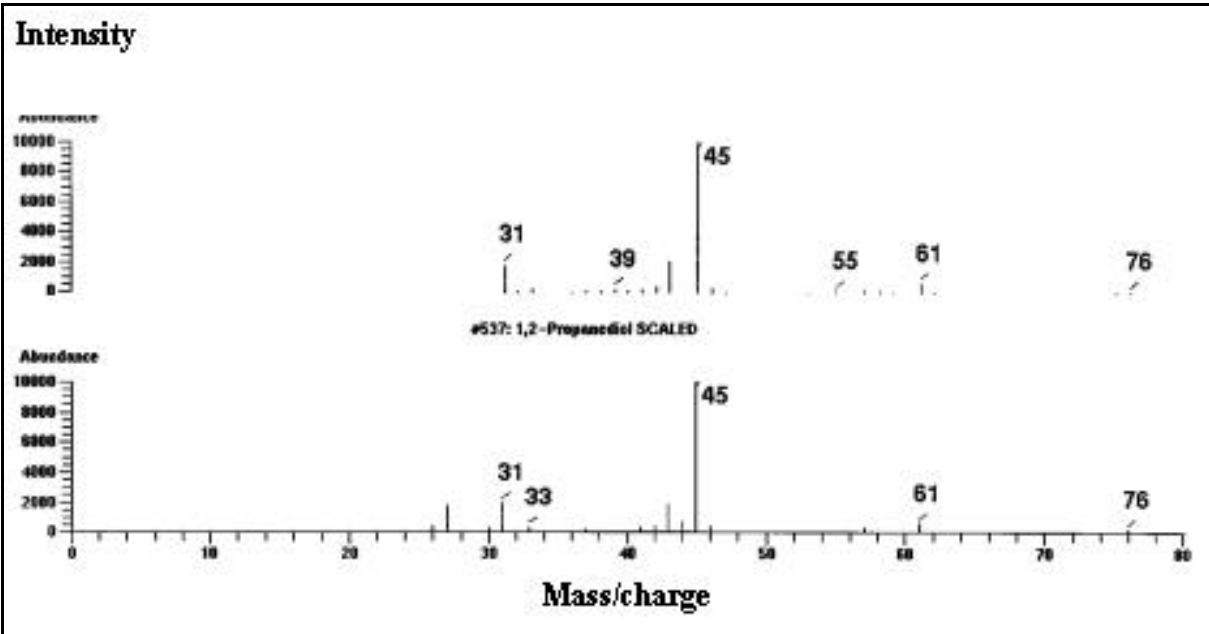

FIGURE 18 Mass spectrum of 1,2 propanediol from sample standard from the computerized library spectra. 


\section{CONCLUSIONS AND RECOMMENDATIONS}

- Analysis of the volatile and semivolatile fractions collected after use of the TOR lubricant indicated that other than contaminants in the collection laboratory, no compounds on the EPA's Target Compound Lists (Tables 2 and 5) were detected in these fractions. The data of these qualitative analyses, given in the various tables in the text, indicate only the relative amounts of the tentatively identified compounds. We recommend that quantitative analysis be performed on the volatile and semivolatile fractions to allow confirmation of the tentatively identified compounds and to obtain absolute amounts of the detected compounds. Additionally, the semivolatile fraction should be analyzed by liquid chromatography/mass spectrometry to identify compounds that are not chromatographable under the temperature program used for determination of semivolatile compounds.

- Introducing the top-of-rail (TOR) lubricant into the wheel/rail interface results in a reduction of almost $60 \%$ of lateral friction force over the forces encountered under dry conditions. This reveals good potential for energy savings, as well as wear reduction, for railroad companies.

- In TOR lubrication, an increase in the angle of attack and axle load results in increased lateral friction and rate of lubricant consumption.

- The most efficient TOR lubricant quantity to be used in the wheel/rail interface must be calculated precisely according to the number of cars, axle loads, train speed, and angle of attack. 


\section{REFERENCES}

[1] Hay, W., MS, Mgt. E., Ph.D., Rail Road Engineering, University of Illinois at UrbanaChampaign, 2 (1982) 669.

[2] Fessler, R. R., and Fenske G. R., "Reducing Friction and Wear in Heavy Vehicles," Multiyear Program Plan, U.S. Dept. of Energy (1999) 27.

[3] Johnson, K. L. Contact Mechanics, Cambridge University Press, Cambridge, U.K. (1985).

[4] Kalker, J. J., "On the Rolling Contact of Two Elastic Bodies in the Presence of Dry Friction," M. S. Thesis, Delft, Netherlands (1967).

[5 Love, A. E. H. "A Treatise on the Mechanical Theory of Elasticity," Cambridge University Press, Cambridge, U.K. (1926).

[6] Ohyama, T., "Adhesion Characteristics of Wheel/Rail System and Its Control at High Speed," Quarterly Reports of RTRI, Vol. 33, No. 1 (1992), 19-30.

[7] Obara, T., "The Behavior of Traction Force at Elliptic Contact between Wheel and Rail," QR of RTRI, Vol. 36, No. 3 (1995).

[8] Kouhbor, K., "Effects of Rail/Wheel Lubrication on Reduction of Energy by Computer Simulation SIMCAR," National Conference Publication - Institute of Engineers, Australia 10th International Wheelset Congress (1992), 311-317.

[9] Sims, R. D., Miller, K. A., and Schepmann, G., "Rail Lubrication Measurement," ASME/IEEE Joint Railroad Conf., (1996), 23-33.

[10] Kramer, J., "Rail Lubrication: Improving Application Systems," Railway Track and Structure, Vol. 92, No. 7 (1996), 19-20.

[11] Kramer, J., "Rail Lubrication: Multiple Choice," Railway Track and Structure, Vol. 91, No. 8 (1995), 14-15.

[12] Alp, A., Erdemir, A., and Kumar, S. "Energy and Wear Analysis in Lubricated Sliding Contact," Wear Proceedings of the $19944^{\text {th }}$ Int. Conf. on Contact Mechanics of Rail-Wheel System, Vol. 191, No.1-2 (1996), 261-264. 
[13] Beret, S., and Trabert, G. R., "Railroad Wheel and Track Lubrication: Assessment of Effectiveness," National Lubricating Grease Institute, Vol. 55, No. 2 (1191), 7-43.

[14] Kumar, S., and Dyavanapalli, V., Tranergy Corp., "Improved Methods for Increasing Wheel/Rail Adhesion in the Presence of Natural Contaminants," Final Report (1997).

[15] Kumar, S., and Dyavanapalli, V., Tranergy Corp., "The LA4000 Lubrication/Adhesion Testing System," (Operating Manual), 2 (1998) 3.

[16] Kumar, S., and Alzoubi, M. F., Illinois Institute of Technology, Wheel/Rail Adhesion Wear Investigation Using A Quarter-Scale Laboratory Test Facility," ASME/IEEE Joint Railroad Conf. (1996) 247-254. 